\title{
NEURAL CORRELATES OF EMOTIONAL MEMORIES: A REVIEW OF EVIDENCE FROM BRAIN IMAGING STUDIES
}

\author{
Florin DOLCOS ${ }^{1)}$, Ekaterina DENKOVA ${ }^{2)}$, and Sanda DOLCOS ${ }^{1)}$ \\ 1) University of Illinois at Urbana-Champaign, USA \\ 2) University of Alberta, Canada
}

\begin{abstract}
What are the neural markers of encoding and retrieving emotional events with increased efficacy? In recent years, this question has captured the attention of cognitive neuroscientists who fervently engaged in addressing it using a multitude of approaches. The present review discusses evidence from brain imaging studies investigating the neural correlates of the memory-enhancing effect of emotion in healthy human participants. The available evidence points to two main mechanisms: one direct involving the medial temporal lobe (MTL), and the other indirect involving the prefrontal cortex (PFC), among other brain regions. Recent studies also showed that these mechanisms are sensitive to aspects relevant to social interactions, as well as to personality-, sex- and age-related differences. Overall, this evidence provides insights into the brain mechanisms that make emotional memories special, and points to possible alterations that could lead to negative affective biases in encoding and remembering emotional memories observed in affective disorders.
\end{abstract}

Key words: emotion-cognition interactions, social cognition, individual differences, modulation hypothesis, neuroimaging, amygdala, hippocampus

Anecdotal and scientific evidence (e.g., Bradley \& Lang, 1994; Christianson, 1992) show that emotionally-charged events tend to be better remembered than neutral events. Typically, the impact of emotion on memory has been investigated at various stages of memory (from the early stages of memory formation - encoding and early consolidation of memory traces - to their retrieval) and according to two orthogonal affective dimensions: arousal and valence ${ }^{1}$ (Lang, Greenwald, Bradley, \& Hamm 1993; Russell, 1980). More recently, however, the importance of other aspects, such as the role of social relevance (Adolphs, 2010) and individual differences (Haas \& Canli, 2008; Hamann \& Canli, 2004) has emerged in emotional memory research. The extant research on the neural correlates of the memory enhancing effect of emotion emphasizes the role of the amygdala (AMY), an almond-shaped group of nuclei located within the medial-temporal lobe (MTL), in the encoding (e.g., Dolcos, LaBar, \& Cabeza, 2004b; Kensinger \& Corkin, 2004; Kensinger \& Schacter, 2006a; Ritchey, Dolcos, \& Cabeza, 2008; Sergerie, Lepage,

Correspondence concerning this article should be addressed to Florin Dolcos, PhD, Psychology Department, Neuroscience Program and The Beckman Institute for Advanced Science \& Technology, University of Illinois at Urbana-Champaign, 405 North Mathews Avenue, Urbana, IL 61801 USA (e-mail: fdolcos@illinois.edu).

${ }^{1}$ Arousal refers to a continuum that varies from calm to excitement, whereas valence refers to a continuum that varies from pleasant to unpleasant, with neutral as an intermediate value (for methods to assess these dimensions, see (Bradley \& Lang, 1994). 
\& Armony, 2006), consolidation (Ritchey et al., 2008), and retrieval (e.g., Dolcos, LaBar, \& Cabeza, 2005; Kensinger \& Schacter, 2005; Sergerie et al., 2006) of emotional memories. Given its multiple connections with core memory structures, as well as with numerous cortical and subcortical regions involved in diverse functions such as perception, emotion, elaborative cognitive processes and social cognition (see reviews by Dolcos \& Denkova, 2008; Dolcos, Iordan, \& Dolcos, 2011; Dolcos, LaBar, \& Cabeza, 2006; Hamann, 2001; LaBar \& Cabeza, 2006; LeDoux, 2000; McGaugh, 2004; Phelps, 2004), AMY in concert with these regions plays a critical role in modulating the emotional and social functions implicated in emotional memory (Buchanan, Tranel, \& Adolphs, 2009; Hamann, 2009).

The emphasis of this review is on evidence from functional neuroimaging studies on healthy human participants investigating the role of the AMY and its interaction with memory-related MTL brain regions, as well as the role of the PFC in the impact of emotion on both initial memory formation and memory retrieval. Moreover it also considers the role of individual differences and the influence of social aspects in the impact of emotion on memory. Following a brief introduction of animal research and the development of neuroimaging methods which have led to the investigation of the neural correlates of emotional memory in humans, the present review discusses the literature in two main sections, as follows. The first section focuses on functional neuroimaging evidence revealing the involvement of the AMY and its interaction with memory-related regions (MTL and PFC) and with other regions involved in emotion processing (Insula), during encoding and retrieval of emotional events; aspects regarding the role of the social dimensions are also discussed. The second section discusses the role of personality, sex, and age differences in the impact of emotion on memory. The review ends with concluding remarks and a brief presentation of open issues and future directions.

\section{Evidence From Animal Research—Modulation vs. Plasticity?}

Historically, considerable evidence of the involvement of AMY in emotional memory has emerged from animal models, which provide the foundation for investigation of neural mechanisms underlying emotional learning and memory in humans (Delgado, Olsson, \& Phelps, 2006; LeDoux, 2000; McGaugh, 2000, 2004; Phelps \& LeDoux, 2005). Animal research has primarily emphasised the role of the AMY in emotional learning and memory, but its specific role continues to be a matter of current debate. The two most influential hypotheses concerning its role are the modulation and the plasticity hypotheses, which posit different involvement of the AMY in emotional memory (Dolcos \& Denkova, 2008). Specifically, while the modulation hypothesis suggests a modulatory role of the AMY during the encoding and consolidation of memory processes occurring in other brain regions (McGaugh, 2000, 2004), the plasticity hypothesis proposes that AMY itself is a site of plasticity ${ }^{2}$ underlying learning and memory of fear conditioning, as well as reconsolidation of the memory trace following retrieval (LeDoux, 2007; LeDoux, 2000). It should be noted that although these hypotheses could be seen as conflicting (e.g., Cahill, Weinberger, Roozendaal, \& McGaugh, 1999; Vazdarjanova \& McGaugh, 1998), in reality they are rather complementary (Fanselow \& LeDoux, 1999; Phelps \& LeDoux, 2005). 
The apparent contradiction seems to result from the fact that the modulation and the plasticity hypotheses tended to be tested with different behavioral paradigms (i.e., inhibitory avoidance $v s$. Pavlovian fear conditioning, respectively) that emphasize different aspects concerning the role of AMY in mediating the impact of emotion on learning and memory (explicit/declarative types of memory vs. implicit/procedural forms of memory). However, given that real-life situations typically involve both declarative and nondeclarative aspects of behavior, and that emotion may influence memory not only during the initial stages but also during the actual retrieval, it is more reasonable to consider both accounts when investigating the neural correlates of the memory-enhancing effect of emotion, rather than considering either one or the other of the mechanisms suggested by the two hypotheses. Evidence from functional neuroimaging studies in humans are actually consistent with this idea (Dolcos \& Denkova, 2008; Dolcos et al., 2011; Dolcos et al., 2004b, 2005).

\section{The Role of Brain Imaging Methods in Exploring the Impact of Emotion on Memory}

Consistent with animal research, human research based on lesion (Adolphs, Cahill, Schul, \& Babinsky, 1997; Adolphs, Tranel, \& Denburg, 2000; Cahill, Babinsky, Markowitsch, \& McGaugh, 1995; LaBar, Gatenby, Gore, LeDoux, \& Phelps, 1998; Phelps, LaBar, Anderson, O'Connor, Fulbright, \& Spencer, 1998) and pharmacological methods (Cahill, Prins, Weber, \& McGaugh, 1994; Strange \& Dolan, 2004; Strange, Hurlemann, \& Dolan, 2003) highlighted the role of the AMY in emotional memory. More recently, however, human research has also greatly benefited from the advent of brain imaging methods, which allowed for the specific investigation of emotional memory in neurologically intact human brain.

Event-Related Designs. A significant contribution to our understanding of the neural mechanisms of memory has been made by the introduction of event-related designs as opposed to blocked designs (D'Esposito, Zarahn, \& Aguirre, 1999; Donaldson \& Buckner, 2001; Rosen, Buckner, \& Dale, 1998). Different from blocked designs, constrained to averaging brain activity to several trials of the same type over time, eventrelated designs allow for analysis of brain imaging data on a stimulus-by-stimulus basis, so that the individual responses to single events can be specifically identified. An important advantage of the event-related over the blocked data is that they can be analyzed and categorised post-hoc according to the subjects' performance. This advantage has proven particularly important in investigating the neural correlates of memory processes, as it allows comparison of brain activity for items that are subsequently remembered vs. forgotten in a memory test, thereby allowing the possibility of establishing a direct link between brain activity and memory performance (Paller \& Wagner, 2002).

\footnotetext{
${ }^{2}$ Note that this nomenclature does not refer to the notion of neuronal plasticity in stricto sensu, as generally accepted in neuroscience linked to memory processes (see Martin, Grimwood, \& Morris, 2000) but rather to the place where plasticity is expected in relationship to processing leading to increased emotional memories, as predicted by the two views. Both the modulation and the plasticity hypotheses predict neuronal plasticity, but while the former view predicts that the amygdala influences plasticity occurring in other brain regions, the latter view poses that the amygdala itself is a site of plasticity that contributes to the memoryenhancing effect of emotion.
} 
The Subsequent Memory Paradigm. One particular event-related experimental paradigm that allows comparison of brain activity according to subjects' memory performance is the so-called subsequent memory paradigm (SMP). Using SMP, one may compare activity for items that are remembered vs. forgotten in a memory test, thus establishing a direct link between brain activity and successful memory performance in individual participants. Comparing brain activity for remembered vs. forgotten items can be done both during the encoding (learning) phase and during the retrieval (test) phase (see Fig. 1). By sorting brain activity recorded during encoding based on whether stimuli processed during the study phase are subsequently remembered $(\mathrm{R})$ or forgotten $(\mathrm{F})$ in a later memory test, one can calculate the so-called difference in memory or Dm effect-i.e., greater encoding activity for remembered than for forgotten items (e.g., Paller, Kutas, Shimamura, \& Squire, 1987; Paller \& Wagner, 2002), and brain regions showing a positive Dm effect $(\mathrm{R}>\mathrm{F})$ are assumed to mediate processes that lead to successful memory encoding, and are associated with encoding success (ES). In the case of retrieval, the contrast "remembered minus forgotten" identifies regions showing greater activity for items in which retrieval was successful (Hits) than for items in which retrieval failed (Misses). The activity difference between remembered vs. forgotten items during retrieval is known as retrieval success (RS) (Prince, Daselaar, \& Cabeza, 2005; Weis, Klaver, Reul, Elger, \& Fernandez, 2004).

In the context of investigating the impact of emotion on memory, one of the main advantages of Dm/ES and RS analyses is that they can take out the confounding effect of general emotion processing and specifically identify brain activity linked to the memoryenhancing effect of emotion (Shafer, Iordan, Cabeza, \& Dolcos, 2011). Specifically, by contrasting the emotional ES/RS to the neutral ES/RS, one can identify the brain regions whose memory-related activity is susceptible to emotional modulation during encoding and/or retrieval. Therefore, neuroimaging studies using event-related designs and the SMP have been greatly influential in revealing brain regions that show an interaction between emotion and memory at different stages of memory processing; basic findings from such studies will be reviewed below.

\section{NeURAl Correlates OF THE MEMORY-ENHancing EFFECT OF EMOTION ON MEMORY}

Based on animal research, human studies have emphasized primarily the role of the AMY and its interaction with memory-related MTL regions in mediating the memoryenhancing effect of emotion. The majority of the studies revealed that activity in AMY, MTL and their interactions are important for memory of negative as well as positive items matched in arousal, suggesting therefore that their involvement is primarily driven by the arousal and not the valence of the information. In addition, neuroimaging studies also demonstrated that AMY and MTL do not interact in isolation, but together with other brain regions, especially with the prefrontal cortex (PFC), whose involvement seems to also be susceptible to valence-related effects. Finally, recent evidence suggests that the enhancing 


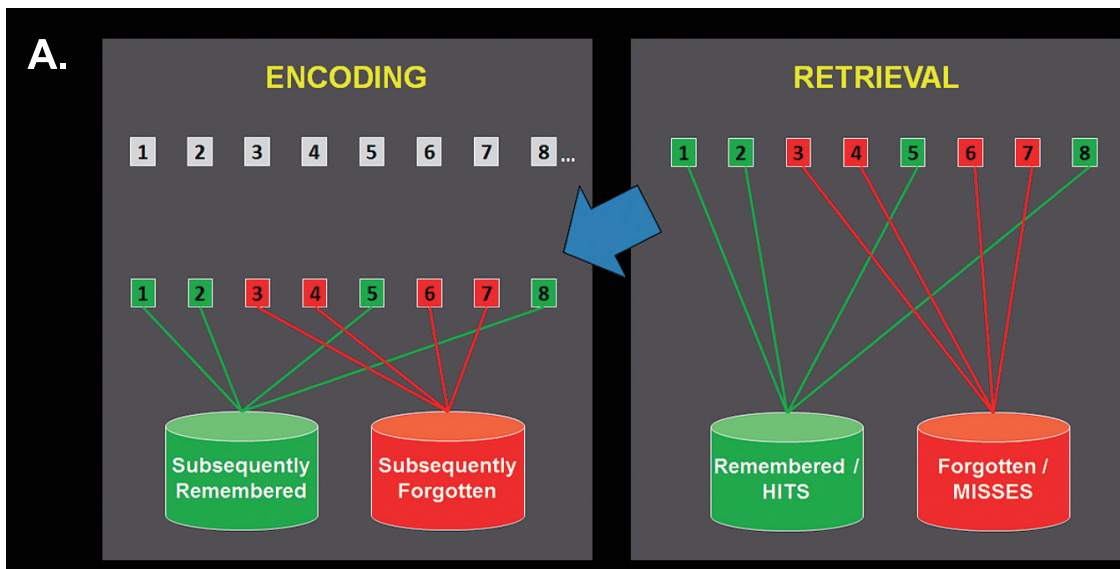

REMEMBERED > FORGOTTEN

( Difference due to Memory $=\mathbf{D m}$ )

$\downarrow$

Encoding Success
HITS > MISSES

$\downarrow$

Retrieval Success (RS)

B.

Emo ES/RS > Neu ES/RS = effect of emotion
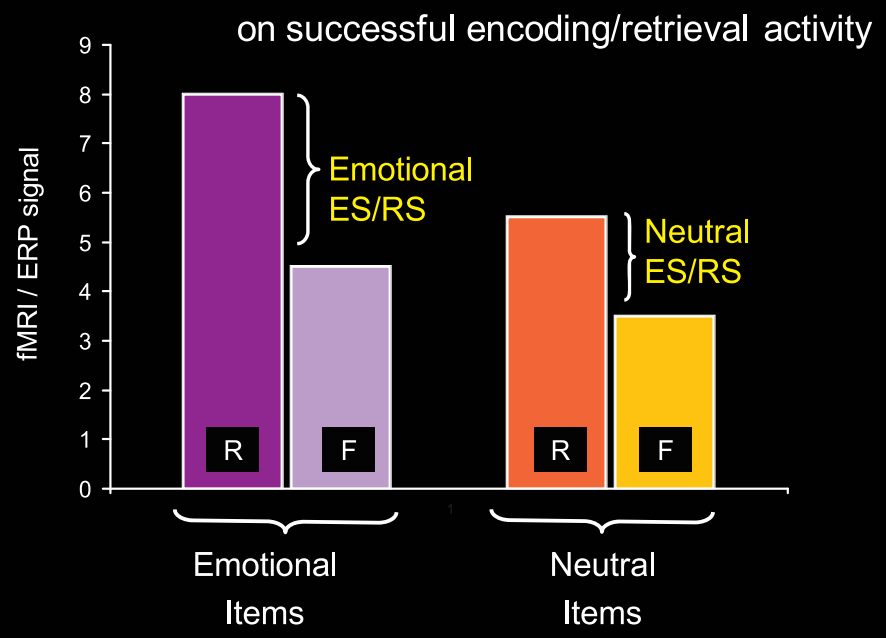

Fig. 1. The subsequent memory paradigm - measuring the impact of emotion on encoding success (ES) and retrieval success (RS) activity. A. General procedure involved in the subsequent memory paradigm (SMP). B. Diagram of the comparisons that allow identification of the brain regions susceptible to emotional ES and RS. R=subsequently remembered items, F= subsequently forgotten items; ERP = Event-Related Potential, fMRI = functional Magnetic Resonance Imaging. From Shafer et al. (2011), with permission. 
effect of emotion on memory can be revealed by a more complex interplay among AMY, MTL, PFC and other emotion-related regions, when besides the typical arousal and valence dimensions other psychological dimensions, such as social relevance, are taken into consideration. Evidence supporting these ideas will be discussed in turn below.

\section{The Role of AMY/MTL and Arousal Effects}

Emotional Memory Encoding. Several functional neuroimaging studies have associated the enhancing effect of emotion on memory with AMY (see reviews by Dolcos \& Denkova, 2008; Dolcos et al., 2006; Hamann, 2001; LaBar \& Cabeza, 2006; Phelps, 2004). Early studies suggested a link between AMY activity at encoding and later retrieval of emotionally arousing material (e.g., Cahill et al., 1996; Hamann, Ely, Grafton, \& Kilts, 1999). However, since they used blocked designs, these studies could not distinguish between brain activity for successfully and unsuccessfully encoded stimuli within participants, and thus could not specifically assess the role of AMY in successful encoding of emotional stimuli, as opposed to linking it to general emotion processing. By contrast, studies involving event-related designs in conjunction with the SMP have allowed identification of the role of AMY and its interactions with memory-related MTL brain regions (e.g., hippocampus-HC) in the memory enhancement by emotion, in neurologically intact human brain (e.g., Dolcos et al., 2004b; Kensinger \& Corkin, 2004; Kensinger \& Schacter, 2006a; Ritchey et al., 2008; Sergerie et al., 2006).

The Role of AMY. Such studies combining event-related designs and the SMP revealed that enhanced memory for arousing stimuli regardless of their valence has been associated with greater successful encoding activity (Emotional Dm $>$ Neutral Dm) in AMY (reviewed in Dolcos \& Denkova, 2008; Dolcos et al., 2006). Moreover, the involvement of precise methods (i.e., anatomically-defined regions of interest-ROIs) in the quantification of the fMRI signal allowed identification with increased specificity of the contribution of various emotion and memory-related MTL subregions (consisting of HC and the surrounding parahippocampal cortices) to the observed effects. Consistent with evidence from animal research (Frey, Bergado-Rosado, Seidenbecher, Pape, \& Frey, 2001; Quirarte, Roozendaal, \& McGaugh, 1997; Roozendaal \& McGaugh, 1997), arousal mediated enhancement of memory was found in the basolateral nucleus of AMY (BLA), as well as in the HC head and the entorhinal cortex (see Fig. 2) (Dolcos et al., 2004b).

Neuroimaging evidence also revealed that the increased AMY activation during memory formation may depend on the level-of processing during encoding (Ritchey, Labar, \& Cabeza, 2011) and be related to the subjective vividness of subsequent memory regardless of arousal and valence (Kensinger, Addis, \& Atapattu, 2011). The latter finding suggests that AMY's involvement may not be always a sign of encoding more details but rather seems to correspond to the subjective feeling of vivid memory. This finding also raises the question of how the subjective factors may influence the formation of emotional memories. In this context, it is worth mentioning that recent evidence also suggests that the role of the AMY may extend beyond successful encoding of general emotional stimuli to include successful encoding of personally and/or socially relevant stimuli (e.g., Botzung, LaBar, Kragel, Miles, \& Rubin, 2010; Harvey, Fossati, \& Lepage, 2007; 

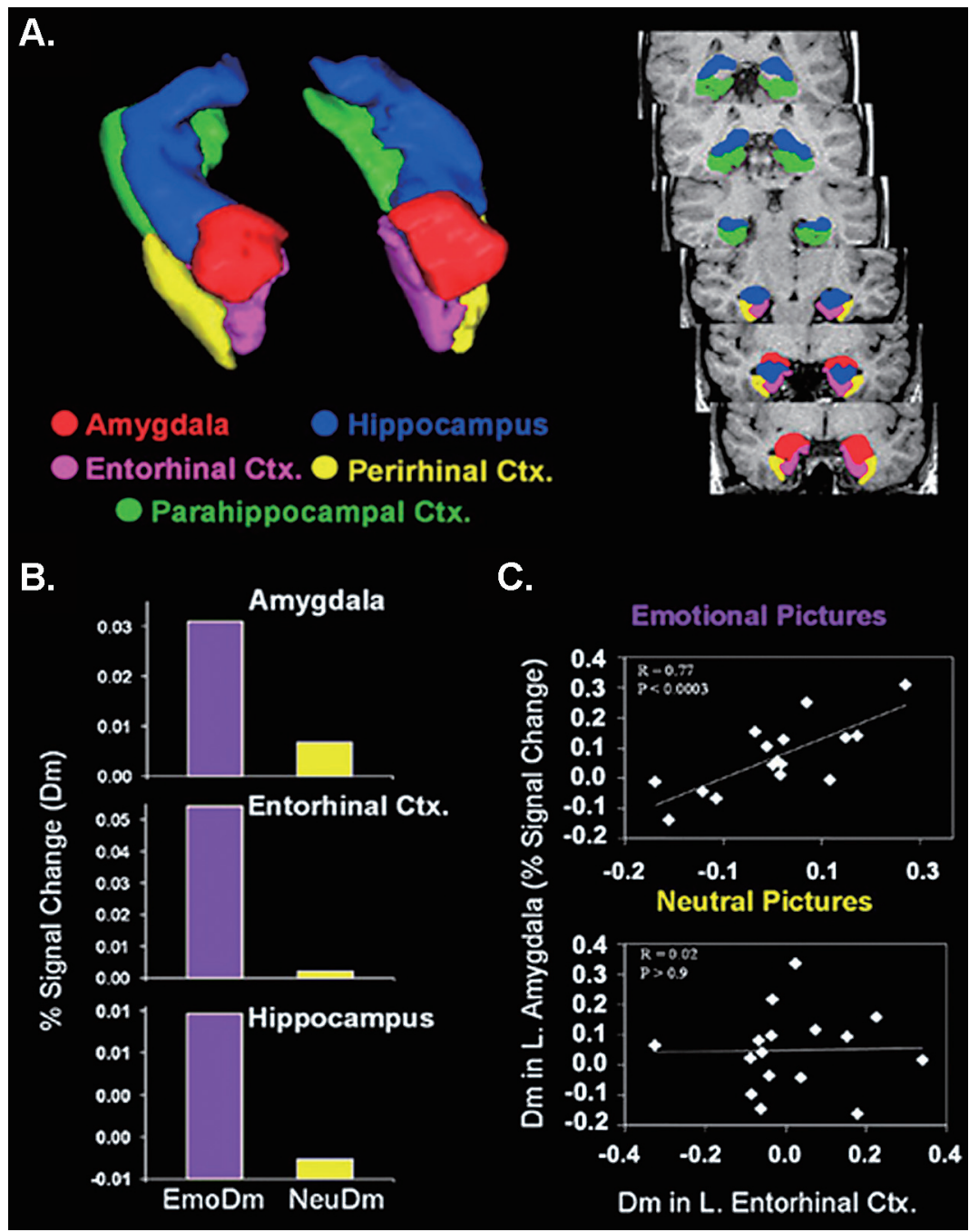

Fig. 2. Evidence of the involvement of amygdala (AMY) and memory-related medial temporal lobe (MTL) regions in emotional memory encoding. A. Three-dimensional view of the anatomically defined Regions of Interest (ROIs) in the AMY and the adjacent MTL memory subregions. The right side panels show coronal views of representative slices illustrating the exact location in the brain of the ROIs. B. Greater emotional (Emo) Dm than neutral (Neu) Dm in AMY and MTL memory system. The bar graphs show greater emotional Dm than and neutral Dm (Emo Dm $>$ Neu $\mathrm{Dm}$ ) in the AMY, Entorhinal Cortex (EC) and Hippocampus (HC). C. Greater correlation between encoding activity in AMY and MTL memory regions for emotional than for neutral pictures. The scatterplots illustrate across-subjects correlations between the Dm activity in the left (L) AMY and the left EC, for emotional and neutral pictures. $\mathrm{Ctx}=$ Cortex, $\mathrm{Dm}=$ Remembered $>$ Forgotten. From Dolcos et al. (2004b), with permission. 
Kleinhans et al., 2007) (see below for a more detailed discussion on this point).

The Role of AMY-MTL Interactions. In addition to evidence highlighting the engagement of AMY during emotional memory encoding, further evidence reveals that arousal-driven emotional memory enhancement effects emerge from interactions between an AMY-based emotion processing system and the memory-related MTL regions (Canli, Zhao, Brewer, Gabrieli, \& Cahill, 2000; Dolcos et al., 2004b; Hamann et al., 1999; Kilpatrick \& Cahill, 2003; Richardson, Strange, \& Dolan, 2004). Specifically, the study by Dolcos et al. (2004b) found that Dm activity in AMY and the MTL memory regions was more strongly correlated with each other for the emotional than for the neutral stimuli (see Fig. 2), thus providing further support for the modulation hypothesis (see also Kensinger \& Corkin, 2004; Kilpatrick \& Cahill, 2003). Noteworthy, there is also evidence that the AMY-MTL interactions contribute to the persistence of emotional memory over time (Ritchey et al., 2008). In Ritchey et al.'s study, participants were scanned while encoding emotionally negative and neutral pictures, then their recognition memory was tested following scanning both after a short delay (20 min after encoding) and after a long delay (1 week after encoding). This manipulation revealed that the AMY-MTL connectivity during encoding was greater for items retrieved after a longer delay, thus suggesting that AMYMTL interactions underlie consolidation and persistence of emotional memories over time.

Recent evidence also shows that although activity in AMY and MTL is driven primarily by arousal, their interaction may depend on valence (Ritchey et al., 2011). Namely, the study by Ritchey et al. (2011) showed that the AMY-MTL interaction was stronger for encoding of negative stimuli, while the interaction between MTL and prefrontal cortex (PFC) was stronger for encoding of positive stimuli (see below. for a discussion on PFC and valence effect), although the basic activation pattern in these regions was not modulated by valence (Ritchey et al., 2011). These findings suggest that the effect of valence may not be always reflected in the overall activity of emotion- and memory-related regions, but it may emerge at the level of their interactions (Mickley Steinmetz, Addis, \& Kensinger, 2010), thus revealing a more complex effect of valence on AMY activity and its interactions.

In sum, the abovementioned studies have provided strong evidence supporting the notion that the memory-enhancing effect of emotion during early stages of memory formation is associated with increased activity and interaction between an emotion-based system involving AMY and a memory-based system involving $\mathrm{HC}$ and the associated MTL memory regions. The available evidence suggests that AMY is involved in memory for both positive and negative stimuli (Murty, Ritchey, Adcock, \& LaBar, 2010), but some exceptions are noted. While the arousal effect may be linked primarily to increased activity in AMY and MTL, the valence effect could be revealed in the connections between regions rather than directly in their activations and involves regions beyond AMY and MTL. It should also be noted that, although overall these findings provide strong evidence for the modulation hypothesis, the AMY findings, showing greater encoding success for emotional than for neutral stimuli are also consistent with the plasticity hypothesis.

Emotional Memory Retrieval. While AMY's involvement in the formation of emotional 
memories has been well documented (for reviews see Dolcos \& Denkova, 2008; Dolcos et al. 2011 ; Dolcos et al., 2006; LaBar \& Cabeza, 2006; Phelps, 2004), until relatively recently its involvement in the retrieval of emotional memories has been more difficult to demonstrate (for review see Buchanan, 2007; see also Ochsner \& Schacter, 2003). This may be partly due to the methodologies for testing memory, using different kinds of events - e.g., laboratory micro-events vs. autobiographical events. Laboratory events are simpler experimenter-generated stimuli, such as lists of words or sets of pictures that are encoded in laboratory settings and retrieved at different intervals following encoding (e.g., minutes, hours, days, weeks, months). By contrast, autobiographical events are events from one's own history that are encoded in real-world settings and may be retrieved after much longer intervals of years and even decades. Hence, retrieval of laboratory events is dissimilar to retrieval of autobiographical events at least in two aspects: time elapsed between encoding and retrieval and self-relevance. However, testing memory with both types of events also presents advantages. While autobiographical events have the advantage of being close to personal real-life events and to cover temporally dispersed past episodes, laboratory events have the advantage to be well controlled experimentally for neuroimaging applications (Maguire, 2001; see also Cabeza et al., 2004).

The Role of AMY. Several studies of retrieval of emotional laboratory events have pointed to the involvement of the AMY. Similar to the early studies of encoding, the early retrieval studies share many of the same limitations, as most of them either used blocked designs that did not allow assessment of the functional neuroimaging data on a trial-bytrial basis (e.g., Dolan, Lane, Chua, \& Fletcher, 2000; Kosslyn et al., 1996; Taylor et al., 1998), or did not compare activity associated with successfully vs. unsuccessfully retrieved items, to identify brain activity specifically associated with retrieval success (e.g., Fossati et al., 2004; Maratos, Dolan, Morris, Henson, \& Rugg, 2001).

Studies involving event-related designs in conjunction with the subsequent memory paradigm have again proven influential in elucidating the role of AMY during successful retrieval of emotional memory (e.g., Dolcos et al., 2005; Kensinger \& Schacter, 2005; Sergerie et al., 2006). For instance, the study by Dolcos et al. (2005) demonstrated that emotionally arousing stimuli (both pleasant and unpleasant) were remembered better than neutral stimuli one year after the initial encoding, and that this effect was associated with greater retrieval success activity in both the AMY and the MTL memory system (see Fig. 3). Importantly, because SMP was used in this study, activity in the AMY reflected a difference between retrieval activity for emotional pictures correctly classified as old (Emotional Hits) and activity for emotional pictures incorrectly classified (Emotional Misses), rather than general emotion processing. These findings provided strong evidence that successful retrieval of emotional memories involves AMY engagement similar to that identified during successful encoding of emotional memories. Furthermore, refined examinations of AMY's activity linked to a differential impact of emotion on recollectionvs. familiarity-based retrieval ${ }^{3}$ pointed to a specific role of this region in the enhancement

\footnotetext{
${ }^{3}$ Recollection-based retrieval refers to remembering specific contextual details of an event (e.g., about the time and place of its occurrence), whereas familiarity-based retrieval refers to only knowing that certain events occurred, but without retrieving specific contextual details (Tulving, 1985).
} 

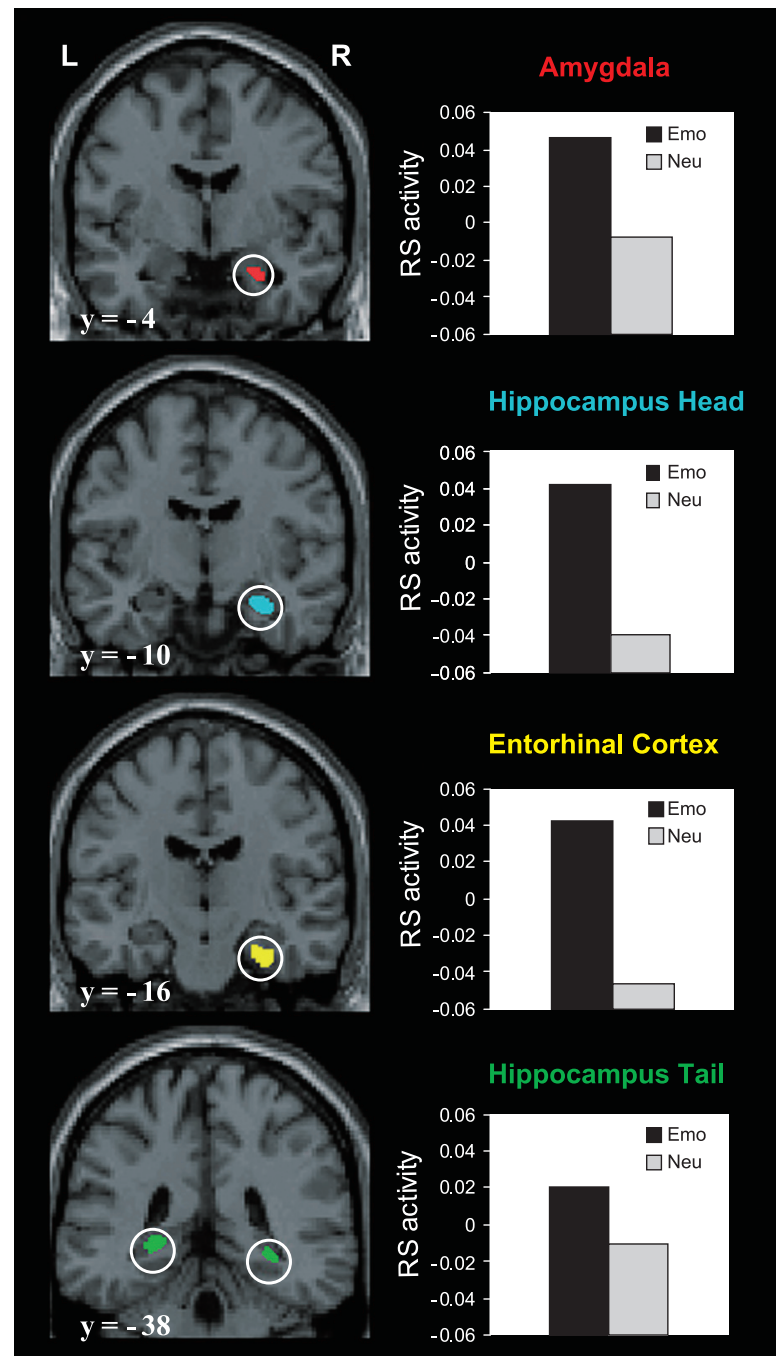

Fig. 3. Evidence of the involvement of amygdala (AMY) and memory-related medial temporal lobe (MTL) regions in emotional memory retrieval. Compared with the neutral (Neu) retrieval success (RS), the overall emotional (Emo) RS was associated with greater activity in the AMY, Entorhinal Cortex (EC) and Hippocampus (HC). The left side panels show representative brain slices with the location of active voxels (in color), as identified in the MTL subregions comparing Emo RS with Neu RS. The right side panels show graphs displaying the emotional and neutral RS expressed in percent signal change, as extracted from the active voxels identified in the MTL subregions. RS $=$ Hits $>$ Misses, $L=$ left, $R=$ right. From Dolcos et al. (2005), with permission.

of recollection rather than familiarity in retrieving emotional memories (Dolcos et al., 2005; Sharot, Delgado, \& Phelps, 2004). This finding provided brain imaging evidence in support of behavioral evidence showing a differential modulation of recollection-based retrieval by emotion (Ochsner, 2000; Talarico, LaBar, \& Rubin, 2004). 
Recent neuroimaging evidence also suggests that AMY plays a role in the successful retrieval of personally relevant events following shorter retention intervals. By investigating basketball fans' memories for specific basketball games, encoded a few days before the scanning session, Botzung, Rubin, Miles, Cabeza, and Labar (2010) showed that AMY activity was modulated by the emotional intensity of the recollected events, and was greater for extremely high- vs. low-intensity events (Botzung, Rubin, et al., 2010). Hence, this study also points to the involvement of AMY in the retrieval of emotional, personally relevant, events (see also Muscatell, Addis, \& Kensinger, 2010; Sharot, Martorella, Delgado, \& Phelps, 2007). Taken together, these studies provide evidence of AMY's involvement in the recollection of high-arousing and personally relevant events, although compared to typical autobiographical memories those events occurred in the relatively near past (from a few days to a few years), as opposed to other personallyrelevant events that may include the whole temporal spectrum of one's own past.

Unlike AMY's involvement in the retrieval of laboratory or relatively recent personally relevant events, which has been well documented, the engagement of the AMY during retrieval of remote autobiographical episodes temporally dispersed in the one's past history is not consistently reported. While some studies found increased activity in the AMY for emotional autobiographical events (Markowitsch et al., 2000; Markowitsch, Vandekerckhove, Lanfermann, \& Russ, 2003), others did not observe such effect (Oddo et al., 2010; Vandekerckhove, Markowitsch, Mertens, \& Woermann, 2005). In the same vein, while some studies reported AMY activity to be modulated by emotional intensity during the early stages of memory retrieval (Daselaar et al., 2008), others failed to observe such an effect (Addis, Moscovitch, Crawley, \& McAndrews, 2004; Maguire \& Frith, 2003).

Several factors could be put forward to account for this inconsistency of AMY's engagement during retrieval of past emotional autobiographical memories (Denkova, Botzung, Scheiber, \& Manning, 2006). First, AMY's decreased activity for more remote, compared to more recently experienced autobiographical events (Maguire \& Frith, 2003), suggests that the former may not be sufficiently vivid and strong to elicit a re-experience of the associated emotion and, therefore, to engage AMY (see also Ochsner \& Schacter, 2000). Second, given that remembering temporally dispersed events from the past is an effortful process, the increased cognitive effort necessary for the retrieval of those memories could divert the attentional resources from the emotional value of recollections (Phan et al., 2004), and hence reduce AMY's engagement, which may depend on the task instructions (Smith, Stephan, Rugg, \& Dolan, 2006; Denkova, Chakrabarty, Dolcos, \& Dolcos, 2011). Finally, it is also possible that differences in image acquisition parameters, in pre-processing steps of data (normalisation and smoothing vs. their absence), and in statistical analyses (whole brain vs. ROI analysis) could, at least partially, account for the inconsistencies in AMY's activation across these studies (Greenberg et al., 2005).

The Role of AMY-MTL Interactions. In addition to evidence highlighting the engagement of the AMY during emotional memory retrieval, further evidence showed increased interactions between this region and the MTL memory regions during emotional retrieval. Namely, neuroimaging investigations reported that AMY and $\mathrm{HC}$ were more 
systematically co-activated during successful recollection of both typical laboratory (Dolcos et al., 2005) and autobiographical (Greenberg et al., 2005) emotional events. These findings are consistent with the idea that AMY and MTL memory system are part of a synergistic mechanism in which emotion enhances recollection and recollection enhances emotion. Emotion may enhance recollection because reinstating the affective context of the original episode is likely to facilitate the recovery of contextual details, such as where, when, and how the original events happened. In turn, recollection of the context surrounding an emotional effect is likely to augment the emotional arousal elicited by the event during retrieval (Dolcos et al., 2005).

There is also evidence that the interaction between the AMY and the MTL memoryrelated regions may be modulated by the involvement of the PFC. For instance, a study by Smith et al. (2006) used dynamic causal modelling to examine the effective connectivity among AMY, HC, and PFC during retrieval, and reported increased bidirectional connectivity between AMY and HC and increased engagement of the medial PFC. Moreover, the latter influenced activity in the AMY and HC during a task requiring explicit recollection of the emotional information, as compared to a task not requiring explicit focus on emotional information. This finding suggested that AMY's involvement can be modulated by one's present goals (Cunningham, Van Bavel, \& Johnsen, 2008), and points to the involvement of the top-down processes through the medial PFC during explicit retrieval of emotional information (see below).

In sum, the studies reviewed above suggest that AMY appears to also play an important role during retrieval of laboratory and relatively recent personally-relevant emotional events. The findings pointing to the involvement of the AMY and its interaction with the MTL during recollection of emotional events extend the modulation hypothesis to retrieval. However, similar to encoding, the AMY's engagement is also consistent with the plasticity hypothesis, particularly if viewed with the reconsolidation account in mind (Nader, Schafe, \& Le Doux, 2000). This suggests that the act of retrieving emotional memory traces render it labile and then requires AMY dependant mechanisms similar to those occurring during initial consolidation, in order to ensure their persistence. Regarding the retrieval of more remote emotional autobiographical memories, due to a series of potential confounding factors, such as one's present goals, motivation, or available cognitive resources, the role of the AMY remains inconclusive.

\section{Beyond AMY-MTL and Arousal Effects: The Role of PFC and Valence-Related Effects}

Although the main focus of the neuroimaging studies of emotion facilitation effect on memory was on AMY and its interaction with memory-related MTL regions, increasing emphasis has been also placed on emotion's ability to influence memory through cognitive processes supported by other brain regions, such as the PFC (Dolcos et al., 2011). It has been suggested that while AMY and MTL are part of basic/direct neurohormonal mechanisms underlying the memory-enhancement effect of emotion, PFC has an indirect/mediated involvement in the formation of emotional memories (e.g., by enhancing strategic, semantic, and working memory processes) (Dolcos \& Denkova, 2008; LaBar \& Cabeza, 2006). Moreover, while AMY and MTL systems are modulated 
primarily by arousal, PFC involvement seems to also be influenced by valence (Kensinger, 2004). Namely, the available evidence suggests that various lateral and medial PFC regions are sensitive to arousal (Dolcos, LaBar, \& Cabeza, 2004a; Kilpatrick \& Cahill, 2003; Sergerie, Lepage, \& Armony, 2005) and valence (Dolcos et al., 2004a; Kensinger \& Schacter, 2006b), probably reflecting their involvement in higher-order emotion processing associated with evaluation of emotional valence and/or cognitive control strategies.

Emotional Memory Encoding. In a series of studies, Kensinger and colleagues found that successful encoding of positive items involved a fronto-parietal network, whereas successful encoding of negative items involved a temporo-occipital network (Kensinger \& Schacter, 2008; Mickley Steinmetz \& Kensinger, 2009). These findings are consistent with other studies revealing that encoding of positive information is associated with activity in specific PFC subregions (Botzung, LaBar, et al., 2010; Dolcos et al., 2004a), probably due to a more elaborative and cognitive resources demanding processing, while encoding of negative information is associated with temporo-occipital regions (Mickley \& Kensinger, 2008), probably due to increased sensory processing. These findings suggest that successful encoding of positive and negative information may depend on different processing, with positive items involving more elaborate processing engaging PFC and contributions from semantic processing (Kapur et al., 1996; Poldrack et al., 1999; Shallice et al., 1994), working memory operations (D’Esposito, Postle, \& Rypma, 2000; Owen et al., 1999; Petrides, 1995), memory control (Anderson et al., 2004), and negative items involving perceptual processing and engaging posterior areas associated with visual processing of emotional information (Vuilleumier, Richardson, Armony, Driver, \& Dolan, 2004);

Emotional Memory Retrieval. Similarly, functional neuroimaging evidence from studies of emotional laboratory (Erk, Martin, \& Walter, 2005; Maratos et al., 2001; Smith, Henson, Dolan, \& Rugg, 2004; Smith et al., 2006) and autobiographical (Botzung, Rubin, et al., 2010; Markowitsch et al., 2003; Piefke, Weiss, Zilles, Markowitsch, \& Fink, 2003) memory retrieval also points to the involvement of PFC influenced by the valence. For instance, increased activity in the medial and/or orbital PFC was associated with retrieval of positive contextual information (Erk et al., 2005), as well as with retrieval of positive personal experiences (Markowitsch et al., 2003; Piefke et al., 2003). The medial orbital PFC has been involved from general emotion processing (Davidson \& Irwin, 1999; Phan, Wager, Taylor, \& Liberzon, 2002) to specific reward-related (Dolan, 2007; O'Doherty, 2004; Rolls, 2004) and self-referential processing (de Greck et al., 2008; Ochsner et al., 2004) (for review see Heinzel \& Northoff, 2009). Therefore, it is possible that the engagement of the medial orbital PFC during retrieval of positive emotional information is linked to the elaboration of self-relevant rewarding experience. Related to this, increased activity in orbital PFC together with increased connectivity with HC was observed in increased memory for socially rewarding stimuli (Tsukiura \& Cabeza, 2008) (see below). Altogether, the available evidence suggests that the involvement of PFC is sensitive to valence and reward circuitry and might reflect higher order cognitive processing during both encoding and retrieval of emotional information. 
Interplays among AMY, MTL, PFC and other Emotion Processing Regions:

\section{The Role of Social Context}

Recent evidence suggests that the PFC involvement goes beyond the two basic emotional dimensions (arousal and valence), and extends to more complex dimensions, such as social relevance. Although fewer studies have investigated the interplay between social cognition and emotion in memory, it seems to be a promising avenue of research, which should shed light on our understanding of emotional memory for more ecologically valid situations, involving interactions with other people and having direct relevance to our own social behavior. To have an adequate social behavior, humans learn social conventions and norms, and distinguish between "what is good and what is bad" (Tsukiura \& Cabeza, 2011a, 2011b; Tsukiura, Shigemune, Nouchi, Kambara, \& Kawashima, 2012); hence, the social dimension appears to be an important factor in emotional memory.

Given that social information may carry emotional significance, it should influence memory through similar mechanisms as emotion, but because of its complexity, it may also engage additional brain systems. Consistent with this idea, there is evidence that because of its complexity, the social dimension needs more elaborative processing (e.g., interpretation of the stimulus meaning depending on the context and individual differences) and seems to enhance memory only when sufficient cognitive resources are available (Sakaki, Niki, \& Mather, 2012). Along this idea, Sakaki et al. (2012) suggested that while processing biologically emotional stimuli is automatic, mediated by increased activity in and connectivity between AMY and visual cortex, processing socially emotional stimuli also depends on more elaborative processes involving enhanced activity in and connectivity between AMY and medial PFC. The involvement of AMY and medial/orbital PFC regions in complex social functions, such as interpreting and monitoring affective reactions or processing reward and punishment, have been recently revealed in neuroimaging studies of emotional memory encoding and retrieval of information having social connotation (e.g., Botzung, LaBar, et al., 2010; Harvey et al., 2007; Somerville, Wig, Whalen, \& Kelley, 2006; Tsukiura \& Cabeza, 2008).

Emotional Memory Encoding. Recent studies suggest that the role of AMY may extend beyond successful encoding of general emotional stimuli to include successful encoding of personally and/or socially relevant stimuli (e.g., Botzung, LaBar, et al., 2010; Harvey et al., 2007; Kleinhans et al., 2007). For instance, by using personally relevant social stimuli (e.g., portions of basketball games), Botzung, LaBar, et al. (2010) reported that AMY activity was preferentially sensitive to highly emotional memories, especially in the context of positively valenced plays. In this context it is interesting to note that increased AMY activity was also observed when people imagined positive future events relative to negative future events (Sharot, 2011; Sharot, Riccardi, Raio, \& Phelps, 2007). It may be possible that basketball fans are more apt to consider positive (vs. negative) plays as more self- and/or socially-defining, and thus this self-referential mode with a social component could lead to greater AMY involvement in the encoding of positive personal episodes (but see Northoff et al., 2009). Therefore, these findings suggest that the involvement of AMY in emotional memory encoding may be influenced by personal 
involvement during encoding of positive episodes, which identifies the social belonging of the individual (see also Markowitsch \& Staniloiua, 2009). This is also in line with evidence pointing to AMY's involvement in social behavior in general (see review by Adolphs, 2010) and in social learning in particular (Davis, Johnstone, Mazzulla, Oler, \& Whalen, 2009).

Besides the AMY, recent research showed increased activity in the medial orbital PFC during encoding of socially relevant stimuli (e.g., Harvey et al., 2007; Tsukiura \& Cabeza, 2008). For instance, increased activity in the orbitofrontal cortex was associated with encoding of attractive faces (e.g., Harvey et al., 2007; Tsukiura \& Cabeza, 2011a). In addition, greater activity in the medial orbital PFC together with enhanced connectivity with the $\mathrm{HC}$ have been observed during encoding of socially rewarding stimuli (i.e., smiling faces) (Tsukiura \& Cabeza, 2008) (see Fig. 4). This finding emphasizes the interplay between reward-related brain regions (i.e., orbital PFC) and memory-related regions (i.e., MTL) during the formation of memory for attractive social stimuli. In contrast, the enhancing effect of socially negative signals (e.g., untrustworthy faces) on memory is mediated by increased activity and connectivity in the Insula and HC (Tsukiura et al., 2012; see also Botzung, LaBar, et al., 2010).

Emotional Memory Retrieval. The involvement of AMY and memory-related MTL regions together with the engagement of the PFC have been revealed not only during encoding but also during retrieval. First, AMY seems sensitive to faces associated with social descriptors (Somerville et al., 2006). Second, increased activity in and interactions between AMY and HC have been observed for socially induced memory errors during retrieval (Edelson, Sharot, Dolan, \& Dudai, 2011), suggesting that social interaction could have long lasting effects on memory through AMY-HC mechanisms. Finally, regarding PFC, the right medial PFC appears to mediate retrieval of social context, while the left medial PFC seems to underlie self-generation in retrieval (Mano et al., 2011), thus revealing that dissociable regions within PFC mediate social processing and selfreferential processing during episodic memory retrieval.

In sum, the recent neuroimaging studies considering the impact of the social aspect on the emotional enhancing effect on memory emphasize the involvement of the AMY, along with $\mathrm{HC}, \mathrm{PFC}$, and the Insula, during both encoding and retrieval. The engagement of the AMY/HC and the medial PFC was linked to memories for positive events, while the $\mathrm{HC}$ and Insula were linked to memory for social items with negative connotations. Thus, when more complex dimensions that are important for our social everyday life are considered, brain regions associated with social cognition, such as the PFC, come to play an important role.

\section{INDIVIDUAL DifFERENCES IN THE NEURAL CORRELATES OF EMOTIONAL MEMORY}

The importance of individual differences is emerging in the research of emotional memory. Investigation of how the neural mechanisms involved in the emotion enhancement effect of memory vary between individuals allows for better understanding 


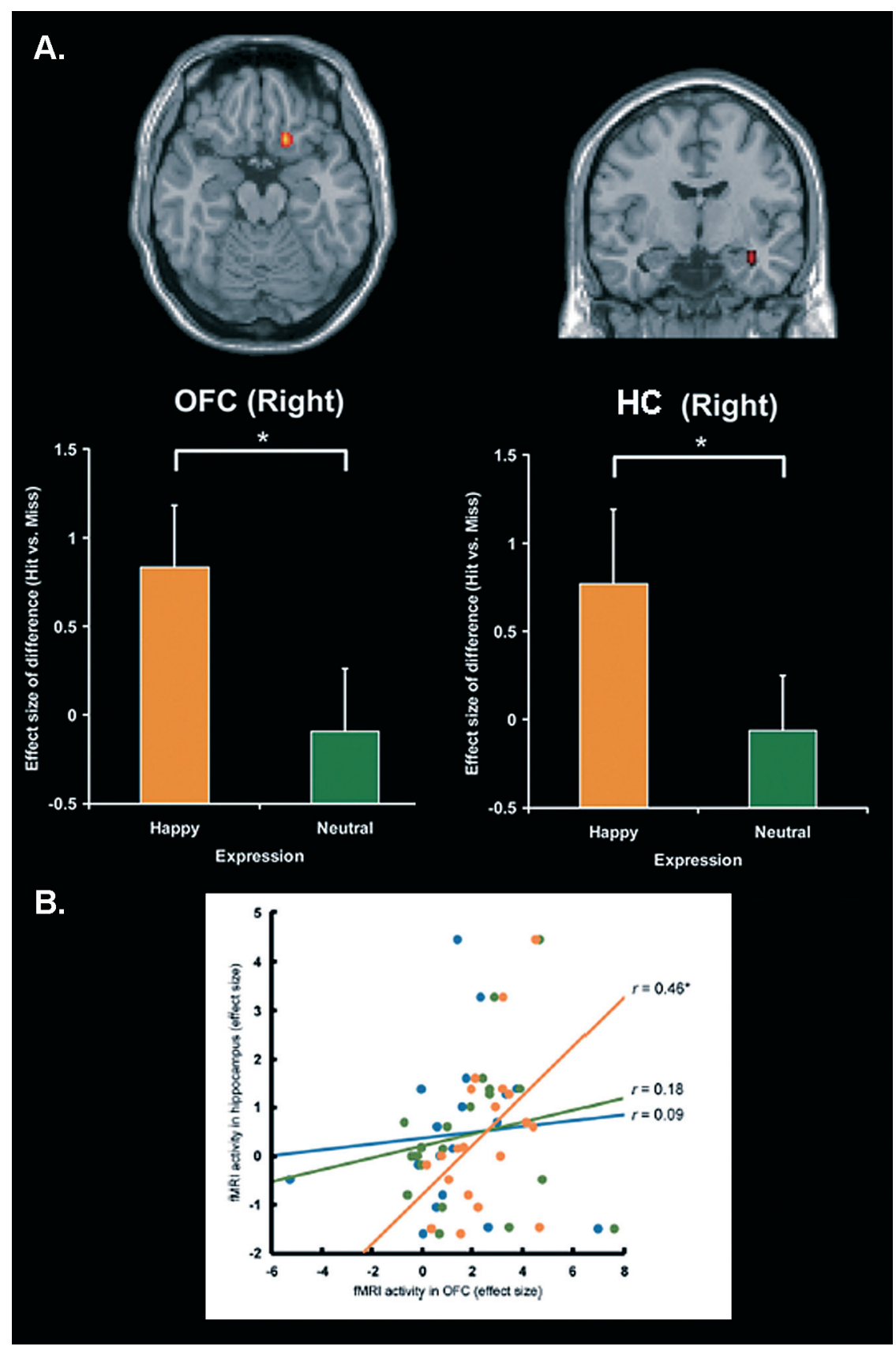

Fig. 4. Evidence for the involvement of orbital PFC and MTL in the enhancement of memory for stimuli with social connotation. Activation and effect sizes in A. the right orbitofrontal cortex (OFC) and hippocampus (HC) during successful encoding of face-name associations for smiling relative to neutral expressions. B. Correlation between OFC and $\mathrm{HC}$ activity was observed for attractive faces (orange) but not for neutral (green) or unattractive (blue) faces. Error bars represent standard error. $* p<0.05$. From Tsukiura and Cabeza (2008 \& 2011a), with permissions. 
of the underlying mechanism in normal conditions and of their changes that lead to emotional memory dysfunctions, as observed in affective disorders (e.g., negative memory biases in depression). In this context, of particular importance along with investigation of individual differences that affect the impact of emotion on memory, such as sex- and age-related, is investigation of personality-related differences linked to general (extraversion, neuroticism) and specific (emotion regulation) traits affecting emotion processing. For instance, understanding the role of habitual use of emotion regulation strategies necessary to efficiently deal with emotionally challenging events/situations, may be critical in preventing the development of affective disorders by reversing possible negative biases in memory for emotional events (Denkova, Dolcos, \& Dolcos, 2012).

Recent evidence suggests that clinical negative affective bias in affective disorders may be linked to excessive AMY involvement and altered control of emotion in the PFC regions (Johnstone, van Reekum, Urry, Kalin, \& Davidson, 2007; Mayberg, 1997). Thus, it becomes critical to understand the factors that might contribute to individual differences in the involvement of the AMY as well as its interaction with cognitive control regions in emotional memory. Such factors could be linked to personality- and sex-related differences in emotional reactivity as well as in emotion control/regulation (e.g., Domes et al., 2010; Mak, Hu, Zhang, Xiao, \& Lee, 2009), which might explain the increased incidence of affective disorders in people high in neuroticism (Bienvenu et al., 2004) and in women (Kessler, 2003). In addition to those factors, investigation of age-related differences in emotion processing also has the potential to contribute to our understanding of the neural mechanisms of altered emotional memory in mood and anxiety disorders as well as potential therapeutic cures, as aging is characterised not only by overall preservation of ability to process emotional information (Keightley, Winocur, Burianova, Hongwanishkul, \& Grady, 2006; Mather, 2006; Phillips, MacLean, \& Allen, 2002), but also by an enhanced ability to control emotion (Gross et al., 1997; Mather \& Knight, 2005); the latter is reflected in a positive bias - i.e., the tendency to attenuate negative emotions and enhance positive emotions (Mather, 2006; Mather \& Carstensen, 2005). Below, we will discuss findings from studies aiming to understand the role of personality-, sex- and age-related difference in the involvement of the AMY and its interaction with memory and/or cognitive control regions in emotional memories.

\section{Personality-Related Differences}

Available behavioral research suggests that affective biases in memory may be related to individual variations in personality traits linked to general emotion processing, such as extraversion and neuroticism (Rubin, Berntsen, \& Bohni, 2008; Young \& Martin, 1981). While factors associated with positive affect, such as extraversion (Costa \& McCrae, 1980; John \& Srivastava, 1999), are associated with positive memories (Rusting, 1999), personality traits associated with negative affect, such as neuroticism, are linked to negative memories (Mayo, 1983; Ruiz-Caballero \& Bermudez, 1995). We recently identified such relationships in the case of retrieving personal memories for real-life events (Denkova et al., 2012). Namely, we showed that extraversion contributed to remembering more positive personal experiences and to maintaining a positive state, 
whereas neuroticism predicted the phenomenological characteristics of negative autobiographical memories; also, only the latter was modulated by sex-related differences.

Regarding the relationship between individual differences in both general emotion processing and specifically linked to emotional memory and brain activity, recent neuroimaging studies have shown that personality traits, such as extraversion and neuroticism, influence the neural correlates of emotion processing across a range of emotional processes, including experience, perception, attention, and memory (Canli, Sivers, Whitfield, Gotlib, \& Gabrieli, 2002; Hamann \& Canli, 2004; Hooker, Verosky, Miyakawa, Knight, \& D'Esposito, 2008; Touryan et al., 2007). It has also been suggested that individual differences in emotional biases linked to personality might be rooted in an attentional network driven primarily by the AMY reactivity during the encoding of emotional stimuli (Haas \& Canli, 2008). Moreover, Hooker et al. (2008) reported that activity in AMY and HC correlate with the level of neuroticism, during fear learning. These findings suggest that neuroticism, which has also been linked to vulnerability to affective disorders (Bienvenu et al., 2004), is associated with an increased sensitivity in the AMY and HC leading to enhanced encoding of negative associations. Of note, evidence of increased AMY to HC volume ratio has been linked to negative memory biases in healthy subjects (Gerritsen et al., 2011), thus suggesting that altered functioning of the AMY is not only disorder specific, but can also be observed in individuals characterized by traits linked to negative affect and hence more prone to develop affective disorders (Hariri et al., 2002; Morey et al., 2011).

\section{Sex-Related Differences}

In our society, it is commonly believed that women are more emotional than men. Consistent at least in part with this widely held belief, researchers have found that women seem to be more emotionally expressive (Kring \& Gordon, 1998), display more extensive knowledge of emotional experience (Barrett, Lane, Sechrest, \& Schwartz, 2000), and recall more emotional autobiographical memories (Davis, 1999; Seidlitz \& Diener, 1998) than men do. Moreover, neuroanatomical research revealed sex-related differences in emotion-related brain regions (e.g., AMY and OFC volumes) (Goldstein et al., 2001; Gur, Gunning-Dixon, Bilker, \& Gur, 2002). Consistent with behavioral and neuroanatomical evidence suggesting differences between men and women, recent evidence from brain imaging studies also pointed to sex-related differences in the involvement of the AMY in emotional memory (e.g., Andreano \& Cahill, 2009; Cahill, 2003; Hamann, 2005). One such notable difference revealed a sex-related hemispheric asymmetry in the role of the AMY in emotional memory encoding (e.g., Cahill et al., 2001; Cahill, Uncapher, Kilpatrick, Alkire, \& Turner, 2004b; Canli, Desmond, Zhao, \& Gabrieli, 2002) (see Fig. 5), with left AMY being associated with successful emotional memory encoding in women and right AMY being associated with successful emotional memory encoding in men (but see Fischer, Sandblom, Nyberg, Herlitz, \& Backman, 2007).

Moreover, this hemispheric lateralisation seems to be confined to the basolateral amygdala (BLA), and observed following longer (2 weeks) but not shorter (minutes) retention intervals (Mackiewicz, Sarinopoulos, Cleven, \& Nitschke, 2006), which 
A. Women > Men

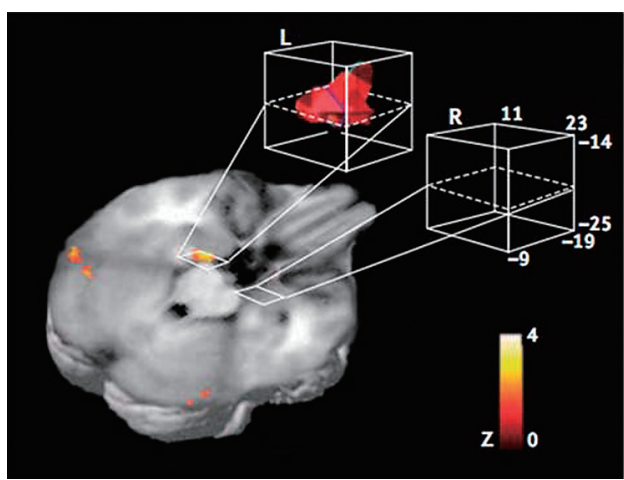

B. Men > Women

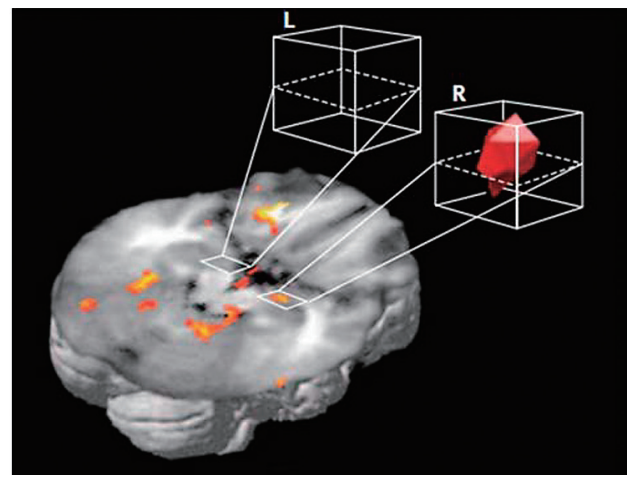

Fig. 5. Sex-related hemispheric asymmetry in AMY. A. Activity in the left AMY while viewing emotionally arousing images was more significantly related to subsequent memory for the images in women than in men, and B. the opposite pattern was observed in the right AMY-greater activity in men than in women. From Cahill et al. (2004b), with author's permission.

suggests that this sex-related lateralisation is influenced by memory consolidation processes. Mackiewicz et al. (2006) reported a left-sided activation in the BLA for delayed recognition memory in women and a right-sided activation in men. Interestingly, these laterality differences were not observed for dorsal AMY, whose activity was associated with anticipatory processes and predicted immediate, but not delayed recognition memory (see also Talmi, Anderson, Riggs, Caplan, \& Moscovitch, 2008).

Further investigation of the impact of sex on AMY involvement during emotional memory encoding suggests that the sex-related lateralisation in the AMY also depends on the sex of the faces. Namely, the left AMY seems to be preferentially involved during successful encoding of female emotional faces in women, while the right AMY is correlated with successful encoding of male emotional faces in men (Armony \& Sergerie, 2007). This finding emphasises the impact of the sex of the faces and not only the sex of the subjects on the lateralisation of the AMY, and thus highlights the potential relation between the perceiver and the stimulus in term of social/biological relevance. In relation to the latter point, the social aspect seems to modulate the differences between women and men. For instance, women seems to have a greater preference for socially-relevant items (e.g., faces and persons vs. scenes) (Proverbio, Adorni, Zani, \& Trestianu, 2008; Proverbio, Zani, \& Adorni, 2008), which suggests that feminine and masculine roles as established by the society, rather than the sex per se, seem to influence these differences in emotional memory (Cahill, Gorski, Belcher, \& Huynh, 2004a).

Overall, the abovementioned findings point to hemispheric differences in the role of the AMY during emotional memory encoding and consolidation. Given the function attributed to the left and right hemisphere in verbal/local vs. nonverbal/global processing, it is possible that the pattern revealed by these studies could be due to the use of verbal/ local strategies during emotional encoding by women and the use of visual spatial/global strategies by men. However, recent evidence suggests that taking into account the social 


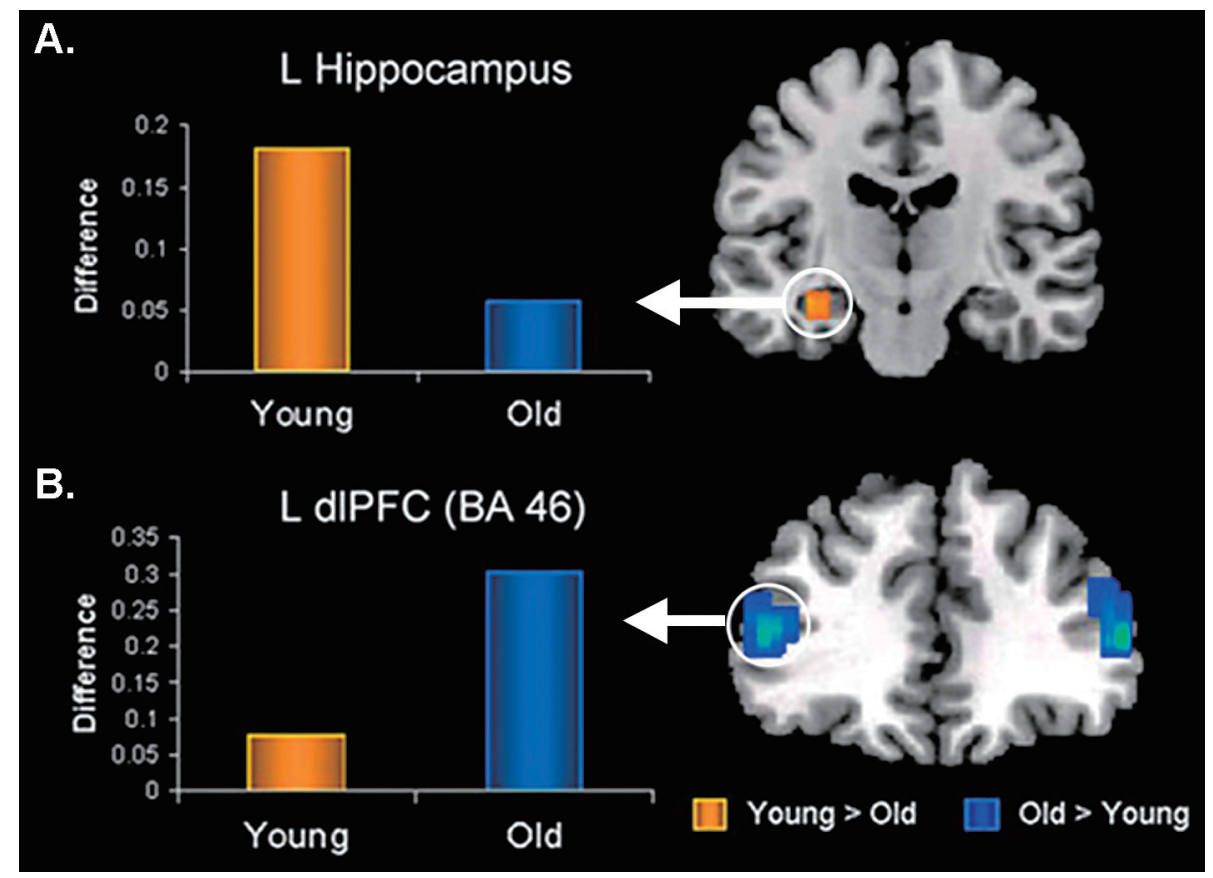

Fig. 6. Opposing age-related changes in the MTL and PFC connectivity with the AMY during emotional memory encoding. Coronal brain view and bar graphs illustrating A. Age-related decreased functional connectivity between $\mathrm{AMY}$ and $\mathrm{HC}$ and $\mathrm{B}$. Age-related enhanced functional connectivity between AMY and dorsolateral PFC (dlPFC) during encoding of memories for negative pictures. $\mathrm{L}=$ left, BA = Brodmann Area. From St Jacques et al. (2009), with permission.

dimension and gender-specific societal roles is also of particular interest in understanding differences between women and men in emotional memory.

\section{Age-Related Differences}

Extant evidence points to a positive affective bias in healthy aging, in the context of preserved emotion function, which also affects emotional memory. According to the Socioemotional Selectivity Theory, SST (Carstensen, Fung, \& Charles, 2003; Carstensen, Isaacowitz, \& Charles, 1999; Mather, 2006; Mather \& Carstensen, 2005), to enhance their well-being, older people prioritise more emotion-related goals (they pursue emotional satisfaction) and demonstrate a positive bias in their emotional memories. This positive affective bias is reflected in older adults' tendency either to spontaneously recall few negative memories (Schlagman, Schulz, \& Kvavilashvili, 2006), to reappraise negative autobiographical memories in a more positive way (Comblain, D'Argembeau, Van der Linden, \& Aldenhoff, 2004), to remember past events in a more positive way (Kennedy, Mather, \& Carstensen, 2004), or to remember more positive than negative personal memories (Fernandes, Ross, Wiegand, \& Schryer, 2008).

Regarding the neural correlates, evidence suggests that preserved emotional 
enhancement of memory in aging is associated with a relative preservation of AMY structure and function (Kensinger \& Schacter, 2008; St Jacques, Dolcos, \& Cabeza, 2009). For instance, the study by St Jacques et al. (2009) showed similar involvement of AMY in emotional memory encoding in both younger and older participants (reflected in greater encoding success activity for emotional than for neutral stimuli Emotional Dm $>$ Neutral $\mathrm{Dm})$. This study also identified decreased functional connectivity between the AMY and MTL, but increased connectivity between the AMY and PFC (see Fig. 6).

These findings suggest an age-related reduction in the contribution of the AMY-MTL mechanisms, which may be compensated by enhanced contribution of AMY-PFC mechanisms to the formation of emotional memories. These age-related differences in the emotional network are consistent with a more general pattern of Posterior- $A$ nterior $S$ hift in $A$ ging (the PASA model)-i.e., diminished engagement of the posterior brain regions compensated by enhanced contribution of the PFC regions (Davis, Dennis, Daselaar, Fleck, \& Cabeza, 2008; Dennis \& Cabeza, 2008). Given that the PASA pattern observed in the cognitive domain is interpreted as reflecting the engagement of compensatory mechanisms (Davis et al., 2008; Grady et al., 1994), the abovementioned findings from the affective domain could also be interpreted as reflecting compensatory engagement of PFC mechanisms as a result of overall diminished contribution of the MTL mechanism. This interpretation is consistent with the behavioral findings that showed overall better memory for emotional than for neutral stimuli in both young and older groups, although the latter group also showed a reduction in the emotional enhancement of memory (possibly as a result of reduced contribution from the direct MTL mechanisms, St Jacques et al., 2009).

On the other hand, given the evidence supporting an enhanced cognitive control of emotion with aging (Gross et al., 1997; Mather \& Knight, 2005), an alternative account for increased PFC involvement is that it reflects enhanced engagement of emotion regulation strategies in older adults. If that was the case, given the evidence that some emotion regulation strategies increase emotional memory (Dillon, Ritchey, Johnson, \& LaBar, 2007), preserved emotional enhancement of memory in aging could be a 'byproduct' of enhanced emotion regulation. These findings involving negative emotions, along with findings from studies investigating similar effects involving positive emotions (see also Kensinger \& Schacter, 2008), are consistent with the positivity bias in remembering emotional memories reported in aging (Mather, 2006; Mather \& Carstensen, 2005). At any rate, these findings not only provide brain imaging evidence supporting the positive affective bias in healthy aging, but may also provide insight into identification of therapeutic approaches that would capitalize on the "elders' wisdom" in controlling emotions to provide effective emotion control strategies aimed at reversing negative affective biases in affective disorders. 


\section{CONCLUSIONS AND FUTURE DiRECTIONS}

The overarching goal of the present review was to discuss findings from brain imaging studies investigating the neural correlates of the memory-enhancing effect of emotion during both encoding and retrieval. The extant evidence points to two main mechanisms involved in the memory-enhancing effect of emotion-one based in the MTL and the other outside of the MTL, involving the PFC, among other regions. These two mechanisms seem to have dissociable contributions to the enhancing effect of emotion: AMY and MTL are part of basic/direct neurohormonal mechanisms underlying the memory-enhancement effect of emotion (bottom-up mechanism), whereas PFC is part of a mechanism (also including the parietal cortex-PC) that has an indirect/mediated involvement in emotional memories, by enhancing strategic, semantic, working memory, and attentional processes (top-down mechanism) (see Fig. 7).

While both mechanisms are sensitive to arousal, the indirect mechanism is also sensitive to valence. In this context, it should be mentioned that the PFC also exerts

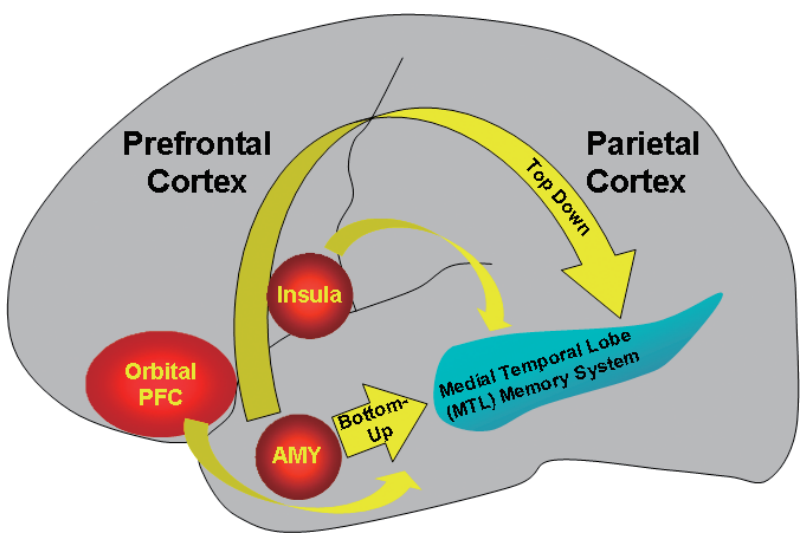

Fig. 7. Diagram summarizing the neural correlates of the memory-enhancing effect of emotion. Two main mechanisms involved in the memory-enhancing effect of emotion were identified - one based in the MTL, involving the AMY and MTL memory regions, and the other outside of the MTL, involving the prefrontal cortex (PFC), among other brain regions. The AMY and MTL are part of basic/direct neurohormonal mechanisms underlying the memory-enhancement effect of emotion (bottom-up mechanism), whereas PFC is part of a mechanism (also including the parietal cortexPC) that has an indirect/mediated involvement in emotional memories, by enhancing strategic, semantic, working memory, and attentional processes (top-down mechanism). While both mechanisms are sensitive to arousal, the indirect mechanism is also sensitive to valence. Investigation of sex-related differences identified a hemispheric asymmetry in the MTL-based system, with the left side being linked to enhanced emotional memory in women and the right side being linked to enhanced emotional memory in men. Moreover, investigation of age-related differences provided evidence that the two systems are differentially affected by aging, which is associated with reduced MTL and enhanced PFC engagement in emotional memory. Finally, investigation of emotional memory for social aspects identified valence-specific engagement of other brain regions that contribute to the memory-enhancement by emotion in social contexts-i.e., memory for socially-relevant information involves activity in and interactions between orbital PFC and MTL, in the case of items with positive connotations, and Insula and MTL for items with negative connotations. Adapted from Dolcos et al., 2011, with permission. 
influences on AMY and MTL activity, depending on the subjects' retrieval focus. Noteworthy, when more complex dimensions, such as social aspects, are taken into consideration, other brain regions are also engaged - increased activity in the orbital PFC together with increased connectivity with the HC enhance memory for socially relevant positive information, while increased activity in the Insula and its connectivity with the $\mathrm{HC}$ enhance memory for social items with negative connotations. Finally, activity in the two basic neural systems is modulated by individual variations linked to personality-, sexand age-related differences. For instance, investigation of sex-related differences identified a hemispheric asymmetry in the MTL-based system, with the left side being linked to enhanced emotional memory in women and the right side being linked to enhanced emotional memory in men. Moreover, investigation of age-related differences provided evidence that the two systems are differentially affected by aging, which is associated with reduced MTL and enhanced PFC engagement in emotional memory.

Despite the significant progress in clarifying the circuitries subserving the memoryenhancing effect of emotion, several issues still need to be investigated in future research. First, the effect of cognitive/executive processes on the involvement of the AMY in memory for emotional events remains unclear. Although emotion regulation research has gained an increasing interest recently (Ochsner \& Gross, 2005), the vast majority of functional neuroimaging studies to date tended to focus on the effect of cognitive control on the immediate emotional experience, rather than on the effect on memory (but see Dolcos, Sung, Denkova, Dixon, \& Dolcos, 2011). Specifically, it is unclear how the engagement of various cognitive control strategies affect the impact of emotion on memory (but see Dillon et al., 2007), and the underlying neural circuitry. Investigation of the neural mechanisms underlying the effect of emotion regulation on memory processes has relevance to understanding clinical conditions such as depression and anxiety, in which emotion dysregulation is often among the core debilitating features.

Second, the role of individual differences in mediating the impact of emotion on memory is still not well understood. While there is evidence that personality traits such as neuroticism and extraversion may induce opposing biases in the memory emotional information (Rusting, 1999; Denkova et al., 2012), and that sex-related differences in memory could be linked to dissociable engagement of emotion regulation strategies (Denkova et al., 2012), the neural circuitry mediating these effects remains poorly investigated.

Third, while the role of the AMY in the retrieval of emotional memories is well documented, its role in the simulation of future emotional events is not known. Previous studies have identified evidence for connectivity between AMY and the rostral anterior cingulate cortex during the imagination of (positive) future events (Sharot et al., 2007), but new tasks able to capture the AMY's involvement in how memory is used to simulate, plan, and predict the future await investigation.

Fourth, while the mechanisms underlying enhanced memory for emotional information when stimuli are presented in isolation have been systematically explored, it remains unclear how emotion enhances the bindings between different components of information (Mather, 2007; Mather \& Nesmith, 2008). Investigations of the neural 
mechanisms underlying the emotional relational memory (Thoresen et al., 2011) has a direct impact on understanding everyday phenomena like forgetting or confusing different elements of an emotional event.

Finally, the mechanisms dissociating negative and positive affective biases in the impact of emotion on memory are also not well understood. While most of the studies tended to focus on negative memories, investigation of positive memories has been largely neglected. Available evidence shows that positive thinking and orientation toward positive experiences promote mental well-being and maintain an overall positive mood (Davidson, 2004; Davidson, Jackson, \& Kalin, 2000), which has become increasingly relevant in today's society. Therefore understanding the role of the AMY and its interplay with other brain regions that lead to opposing affective biases in encoding, consolidation, and retrieval of emotional memories is likely to have implications for addressing a variety of issues relevant to both healthy everyday life and clinical behavior.

\section{REFERENCES}

Addis, D. R., Moscovitch, M., Crawley, A. P., \& McAndrews, M. P. 2004. Recollective qualities modulate hippocampal activation during autobiographical memory retrieval. Hippocampus, 14, 752-762.

Adolphs, R. 2010. What does the amygdala contribute to social cognition? Annals of the New York Academy of Sciences, 1191, 42-61.

Adolphs, R., Cahill, L., Schul, R., \& Babinsky, R. 1997. Impaired declarative memory for emotional material following bilateral amygdala damage in humans. Learning and Memory, 4, 291-300.

Adolphs, R., Tranel, D., \& Denburg, N. 2000. Impaired emotional declarative memory following unilateral amygdala damage. Learning and Memory, 7, 180-186.

Anderson, M. C., Ochsner, K. N., Kuhl, B., Cooper, J., Robertson, E., Gabrieli, S. W., et al. 2004. Neural Systems Underlying the Suppression of Unwanted Memories. Science, 303, 232-235.

Andreano, J. M., \& Cahill, L. 2009. Sex influences on the neurobiology of learning and memory. Learning and Memory, 16, 248-266.

Armony, J. L., \& Sergerie, K. 2007. Own-sex effects in emotional memory for faces. Neuroscience Letters, 426, 1-5.

Barrett, L. F., Lane, R., Sechrest, L., \& Schwartz, G. 2000. Sex differences in emotional awareness. Personality and Social Psychology Bulletin, 26, 1027-1035.

Bienvenu, O. J., Samuels, J. F., Costa, P. T., Reti, I. M., Eaton, W. W., \& Nestadt, G. 2004. Anxiety and depressive disorders and the five-factor model of personality: a higher- and lower-order personality trait investigation in a community sample. Depression and Anxiety, 20, 92-97.

Botzung, A., LaBar, K. S., Kragel, P., Miles, A., \& Rubin, D. C. 2010. Component neural systems for the creation of emotional memories during free viewing of a complex, real-world event. Frontiers in Human Neuroscience, 4, doi:10.3389/fnhum.2010.0034.

Botzung, A., Rubin, D. C., Miles, A., Cabeza, R., \& Labar, K. S. 2010. Mental hoop diaries: emotional memories of a college basketball game in rival fans. Journal of Neuroscience, 30, 2130-2137.

Bradley, M. M., \& Lang, P. J. 1994. Measuring emotion: The self-assessment manikin and the semantic differential. Journal of Behavior Therapy \& Experimental Psychiatry, 25, 49-59.

Buchanan, T., Tranel, D., \& Adolphs, R. 2009. The human amygdala in social function. In P. Whalen \& E. Phelps (Eds.), The Human Amygdala (pp. 289-318). New York: Guilford Publications.

Buchanan, T. W. 2007. Retrieval of emotional memories. Psychological Bulletin, 133, 761-779.

Cabeza, R., Prince, S. E., Daselaar, S. M., Greenberg, D. L., Budde, M., Dolcos, F., et al. 2004. Brain activity during episodic retrieval of autobiographical and laboratory events: an fMRI study using a novel photo paradigm. Journal of Cognitive Neuroscience, 16, 1583-1594.

Cahill, L. 2003. Sex-related influences on the neurobiology of emotionally influenced memory. Annals of 
the New York Academy of Sciences, 985, 163-173.

Cahill, L., Babinsky, R., Markowitsch, H. J., \& McGaugh, J. L. 1995. The amygdala and emotional memory. Nature, 377, 295-296.

Cahill, L., Gorski, L., Belcher, A., \& Huynh, Q. 2004a. The influence of sex versus sex-related traits on longterm memory for gist and detail from an emotional story. Consciousness and Cognition, 13, 391-400.

Cahill, L., Haier, R. J., Fallon, J., Alkire, M. T., Tang, C., Keator, D., et al. 1996. Amygdala activity at encoding correlated with long-term, free recall of emotional information. Proceedings of the National Academy of Sciences of the United States of America, 93, 8016-8021.

Cahill, L., Haier, R. J., White, N. S., Fallon, J., Kilpatrick, L., Lawrence, C., et al. 2001. Sex-related difference in amygdala activity during emotionally influenced memory storage. Neurobiology of Learning and Memory, 75, 1-9.

Cahill, L., Prins, B., Weber, M., \& McGaugh, J. L. 1994. Beta-adrenergic activation and memory for emotional events. Nature, 371, 702-704.

Cahill, L., Uncapher, M., Kilpatrick, L., Alkire, M. T., \& Turner, J. 2004b. Sex-related hemispheric lateralization of amygdala function in emotionally influenced memory: an FMRI investigation. Learning and Memory, 11, 261-266.

Cahill, L., Weinberger, N. M., Roozendaal, B., \& McGaugh, J. L. 1999. Is the amygdala a locus of "conditioned fear"? Some questions and caveats. Neuron, 23, 227-228.

Canli, T., Desmond, J. E., Zhao, Z., \& Gabrieli, J. D. 2002. Sex differences in the neural basis of emotional memories. Proceedings of the National Academy of Sciences of the United States of America, 99, 10789-10794.

Canli, T., Sivers, H., Whitfield, S. L., Gotlib, I. H., \& Gabrieli, J. D. 2002. Amygdala response to happy faces as a function of extraversion. Science, 296, 2191.

Canli, T., Zhao, Z., Brewer, J., Gabrieli, J. D., \& Cahill, L. 2000. Event-related activation in the human amygdala associates with later memory for individual emotional experience. Journal of Neuroscience, 20, RC99.

Carstensen, L. L., Fung, H. H., \& Charles, S. T. 2003. Socioemotional selectivity theory and the regulation of emotion in the second half of life. Motivation and Emotion, 27, 103-123.

Carstensen, L. L., Isaacowitz, D. M., \& Charles, S. T. 1999. Taking time seriously. A theory of socioemotional selectivity. American Psychologist, 54, 165-181.

Christianson, S.-Å. 1992. Handbook of emotion and memory: Research and theory. Hillsdale, NJ: Erlbaum.

Comblain, C., D’Argembeau, A., Van der Linden, M., \& Aldenhoff, L. 2004. The effect of ageing on the recollection of emotional and neutral pictures. Memory, 12, 673-684.

Costa, P. T., Jr., \& McCrae, R. R. 1980. Influence of extraversion and neuroticism on subjective well-being: happy and unhappy people. Journal of Personality and Social Psychology, 38, 668-678.

Cunningham, W. A., Van Bavel, J. J., \& Johnsen, I. R. 2008. Affective flexibility: evaluative processing goals shape amygdala activity. Psychological Sciences, 19, 152-160.

D’Esposito, M., Postle, B. R., \& Rypma, B. 2000. Prefrontal cortical contributions to working memory: evidence from event-related fMRI studies. Experimental Brain Research, 133, 3-11.

D’Esposito, M., Zarahn, E., \& Aguirre, G. K. 1999. Event-related functional MRI: implications for cognitive psychology. Psychological Bulletin, 125, 155-164.

Daselaar, S. M., Rice, H. J., Greenberg, D. L., Cabeza, R., LaBar, K. S., \& Rubin, D. C. 2008. The spatiotemporal dynamics of autobiographical memory: neural correlates of recall, emotional intensity, and reliving. Cerebral Cortex, 18, 217-229.

Davidson, R. J. 2004. Well-being and affective style: neural substrates and biobehavioural correlates. Philosophical Transactions of the Royal Society B: Biological Sciences, 359, 1395-1411.

Davidson, R. J., \& Irwin, W. 1999. The functional neuroanatomy of emotion and affective style. Trends in Cognitive Sciences, 3, 11-21.

Davidson, R. J., Jackson, D. C., \& Kalin, N. H. 2000. Emotion, plasticity, context, and regulation: perspectives from affective neuroscience. Psychological Bulletin, 126, 890-909.

Davis, F. C., Johnstone, T., Mazzulla, E. C., Oler, J. A., \& Whalen, P. J. 2009. Regional response differences across the human amygdaloid complex during social conditioning. Cerebral Cortex, 20, 612-621.

Davis, P. J. 1999. Gender differences in autobiographical memory for childhood emotional experiences. Journal of Personality and Social Psychology, 76, 498-510. 
Davis, S. W., Dennis, N. A., Daselaar, S. M., Fleck, M. S., \& Cabeza, R. 2008. Que PASA? The posterioranterior shift in aging. Cerebral Cortex, 18, 1201-1209.

de Greck, M., Rotte, M., Paus, R., Moritz, D., Thiemann, R., Proesch, U., et al. 2008. Is our self based on reward? Self-relatedness recruits neural activity in the reward system. Neuroimage, 39, 2066-2075.

Delgado, M. R., Olsson, A., \& Phelps, E. A. 2006. Extending animal models of fear conditioning to humans. Biological Psychology, 73, 39-48.

Denkova, E., Botzung, A., Scheiber, C., \& Manning, L. 2006. Implicit emotion during recollection of past events: a nonverbal fMRI study. Brain Research, 1078, 143-150.

Denkova, E., Chakrabarty, T., Dolcos, S., \& Dolcos, F. 2011. Brain imaging investigation of the neural correlates of emotional autobiographical recollection. Journal of Visualized Experiments, 54, doi: $10.3791 / 2396$.

Denkova, E., Dolcos, S., \& Dolcos, F. 2012. Reliving Emotional Personal Memories: Affective Biases Linked to Personality and Sex-Related Differences. Emotion, 12, 515-528.

Dennis, N. A., \& Cabeza, R. 2008. Neuroimaging of healthy cognitive aging. In F. I. M. Craik \& T. A. Salthouse (Eds.), Handbook of aging and cognition: Third edition (pp. 1-54). Mahwah, NJ: Erlbaum.

Dillon, D. G., Ritchey, M., Johnson, B. D., \& LaBar, K. S. 2007. Dissociable effects of conscious emotion regulation strategies on explicit and implicit memory. Emotion, 7, 354-365.

Dolan, R. J. 2007. The human amygdala and orbital prefrontal cortex in behavioural regulation. Philosophical Transactions of the Royal Society B: Biological Sciences, 362, 787-799.

Dolan, R. J., Lane, R., Chua, P., \& Fletcher, P. 2000. Dissociable temporal lobe activations during emotional episodic memory retrieval. Neuroimage, 11, 203-209.

Dolcos, F., \& Denkova, E. 2008. Neural Correlates of Encoding Emotional Memories: A Review of Functional Neuroimaging Evidence. Cell Science Reviews, 5, 78-122.

Dolcos, F., Iordan, A. D., \& Dolcos, S. 2011. Neural correlates of emotion-cognition interactions: A review of evidence from brain imaging investigations. Journal of Cognitive Psychology (Hove), 23, 669-694.

Dolcos, F., LaBar, K. S., \& Cabeza, R. 2004a. Dissociable effects of arousal and valence on prefrontal activity indexing emotional evaluation and subsequent memory: an event-related fMRI study. Neuroimage, 23, 64-74.

Dolcos, F., LaBar, K. S., \& Cabeza, R. 2004b. Interaction between the amygdala and the medial temporal lobe memory system predicts better memory for emotional events. Neuron, 42, 855-863.

Dolcos, F., LaBar, K. S., \& Cabeza, R. 2005. Remembering one year later: role of the amygdala and the medial temporal lobe memory system in retrieving emotional memories. Proceedings of the National Academy of Sciences of the United States of America, 102, 2626-2631.

Dolcos, F., LaBar, K. S., \& Cabeza, R. 2006. The memory-enhancing effect of emotion: Functional neuroimaging evidence. In B. Uttl, N. Ohta \& A. L. Siegenthaler (Eds.), Memory and emotion: Interdisciplinary perspectives (pp. 107-134). Malden, MA: Blackwell Publishing.

Dolcos, S., Sung, K., Denkova, E., Dixon, R. A., \& Dolcos, F. 2011. Brain imaging investigation of the neural correlates of emotion regulation. Journal of Visualized Experiments, 54, doi:10.3791/2430.

Domes, G., Schulze, L., Bottger, M., Grossmann, A., Hauenstein, K., Wirtz, P. H., et al. 2010. The neural correlates of sex differences in emotional reactivity and emotion regulation. Human Brain Mapping, 31, 758-769.

Donaldson, D. I., \& Buckner, R. L. 2001. Effective paradigm design. In P. Jezzard, P.M. Matthews \& S. M. Smith (Eds.), Functional MRI: an introduction to methods (pp. 177-198). New York: Oxford University Press.

Edelson, M., Sharot, T., Dolan, R. J., \& Dudai, Y. 2011. Following the crowd: brain substrates of long-term memory conformity. Science, 333, 108-111.

Erk, S., Martin, S., \& Walter, H. 2005. Emotional context during encoding of neutral items modulates brain activation not only during encoding but also during recognition. Neuroimage, 26, 829-838.

Fanselow, M. S., \& LeDoux, J. E. 1999. Why we think plasticity underlying Pavlovian fear conditioning occurs in the basolateral amygdala. Neuron, 23, 229-232.

Fernandes, M., Ross, M., Wiegand, M., \& Schryer, E. 2008. Are the memories of older adults positively biased? Psychology and Aging, 23, 297-306.

Fischer, H., Sandblom, J., Nyberg, L., Herlitz, A., \& Backman, L. 2007. Brain activation while forming memories of fearful and neutral faces in women and men. Emotion, 7, 767-773. 
Fossati, P., Hevenor, S. J., Lepage, M., Graham, S. J., Grady, C., Keightley, M. L., et al. 2004. Distributed self in episodic memory: neural correlates of successful retrieval of self-encoded positive and negative personality traits. Neuroimage, 22, 1596-1604.

Frey, S., Bergado-Rosado, J., Seidenbecher, T., Pape, H. C., \& Frey, J. U. 2001. Reinforcement of early longterm potentiation (early-LTP) in dentate gyrus by stimulation of the basolateral amygdala: heterosynaptic induction mechanisms of late-LTP. Journal of Neuroscience, 21, 3697-3703.

Gerritsen, L., Rijpkema, M., van Oostrom, I., Buitelaar, J., Franke, B., Fernández, G., et al. 2011. Amygdala to hippocampal volume ratio is associated with negative memory bias in healthy subjects. Psychological Medicine, 11, 1-9.

Goldstein, J. M., Seidman, L. J., Horton, N. J., Makris, N., Kennedy, D. N., Caviness, V. S., Jr., et al. 2001. Normal sexual dimorphism of the adult human brain assessed by in vivo magnetic resonance imaging. Cerebral Cortex, 11, 490-497.

Grady, C. L., Maisog, J. M., Horwitz, B., Ungerleider, L. G., Mentis, M. J., Salerno, J. A., et al. 1994. Agerelated changes in cortical blood flow activation during visual processing of faces and location. Journal of Neuroscience, 14, 1450-1462.

Greenberg, D. L., Rice, H. J., Cooper, J. J., Cabeza, R., Rubin, D. C., \& Labar, K. S. 2005. Co-activation of the amygdala, hippocampus and inferior frontal gyrus during autobiographical memory retrieval. Neuropsychologia, 43, 659-674.

Gross, J. J., Carstensen, L. L., Pasupathi, M., Tsai, J., Skorpen, C. G., \& Hsu, A. Y. 1997. Emotion and aging: experience, expression, and control. Psychology and Aging, 12, 590-599.

Gur, R. C., Gunning-Dixon, F., Bilker, W. B., \& Gur, R. E. 2002. Sex differences in temporo-limbic and frontal brain volumes of healthy adults. Cerebral Cortex, 12, 998-1003.

Haas, B. W., \& Canli, T. 2008. Emotional memory function, personality structure and psychopathology: a neural system approach to the identification of vulnerability markers. Brain Research Reviews, 58, $71-84$.

Hamann, S. 2001. Cognitive and neural mechanisms of emotional memory. Trends in Cognitive Sciences, $\mathbf{5}$, 394-400.

Hamann, S. 2005. Sex differences in the responses of the human amygdala. Neuroscientist, 11, 288-293.

Hamann, S., \& Canli, T. 2004. Individual differences in emotion processing. Current Opinion in Neurobiology, 14, 233-238.

Hamann, S. 2009. The human amygdala and memory. In J. P. Whalen \& E. Phelps (Eds.), The human amygdala (pp. 177-203). New York: Guilford Press.

Hamann, S., Ely, T. D., Grafton, S. T., \& Kilts, C. D. 1999. Amygdala activity related to enhanced memory for pleasant and aversive stimuli. Nature Neuroscience, 2, 289-293.

Hariri, A. R., Mattay, V. S., Tessitore, A., Kolachana, B., Fera, F., Goldman, D., et al. 2002. Serotonin transporter genetic variation and the response of the human amygdala. Science, 297, 400-403.

Harvey, P. O., Fossati, P., \& Lepage, M. 2007. Modulation of memory formation by stimulus content: specific role of the medial prefrontal cortex in the successful encoding of social pictures. Journal of Cognitive Neuroscience, 19, 351-362.

Heinzel, A., \& Northoff, G. 2009. Emotional feeling and the orbitomedial prefrontal cortex: Theoretical and empirical considerations. Philosophical Psychology, 22, 443-464.

Hooker, C. I., Verosky, S. C., Miyakawa, A., Knight, R. T., \& D’Esposito, M. 2008. The influence of personality on neural mechanisms of observational fear and reward learning. Neuropsychologia, 46, 2709-2724.

John, O. P., \& Srivastava, S. 1999. The Big Five Trait Taxonomy: History, Measurement, and Theoretical Perspectives. In L. A. Pervin \& O. P. John (Eds.), Handbook of Personality: Theory and Research (2nd ed. ed., pp. 102-138). New York: Guilford Press.

Johnstone, T., van Reekum, C. M., Urry, H. L., Kalin, N. H., \& Davidson, R. J. 2007. Failure to regulate: counterproductive recruitment of top-down prefrontal-subcortical circuitry in major depression. Journal of Neuroscience, 27, 8877-8884.

Kapur, S., Tulving, E., Cabeza, R., McIntosh, A. R., Houle, S., \& Craik, F. I. 1996. The neural correlates of intentional learning of verbal materials: a PET study in humans. Brain Research: Cognitive Brain Research, 4, 243-249.

Keightley, M. L., Winocur, G., Burianova, H., Hongwanishkul, D., \& Grady, C. L. 2006. Age effects on 
social cognition: faces tell a different story. Psychology and Aging, 21, 558-572.

Kennedy, Q., Mather, M., \& Carstensen, L. L. 2004. The role of motivation in the age-related positivity effect in autobiographical memory. Psychological Science, 15, 208-214.

Kensinger, E. A. 2004. Remembering emotional experiences: the contribution of valence and arousal. Reviews in the Neurosciences, 15, 241-251.

Kensinger, E. A., Addis, D. R., \& Atapattu, R. K. 2011. Amygdala activity at encoding corresponds with memory vividness and with memory for select episodic details. Neuropsychologia, 49, 663-673.

Kensinger, E. A., \& Corkin, S. 2004. Two routes to emotional memory: distinct neural processes for valence and arousal. Proceedings of the National Academy of Sciences of the United States of America, 101, 3310-3315.

Kensinger, E. A., \& Schacter, D. L. 2005. Retrieving accurate and distorted memories: neuroimaging evidence for effects of emotion. Neuroimage, 27, 167-177.

Kensinger, E. A., \& Schacter, D. L. 2006a. Amygdala activity is associated with the successful encoding of item, but not source, information for positive and negative stimuli. Journal of Neuroscience, 26, 2564-2570.

Kensinger, E. A., \& Schacter, D. L. 2006b. Processing emotional pictures and words: effects of valence and arousal. Cognitive Affective and Behavioral Neuroscience, 6, 110-126.

Kensinger, E. A., \& Schacter, D. L. 2008. Neural processes supporting young and older adults' emotional memories. Journal of Cognitive Neuroscience, 20, 1161-1173.

Kessler, R. C. 2003. Epidemiology of women and depression. Journal of Affective Disorders, 74, 5-13.

Kilpatrick, L., \& Cahill, L. 2003. Amygdala modulation of parahippocampal and frontal regions during emotionally influenced memory storage. Neuroimage, 20, 2091-2099.

Kleinhans, N. M., Johnson, L. C., Mahurin, R., Richards, T., Stegbauer, K. C., Greenson, J., et al. 2007. Increased amygdala activation to neutral faces is associated with better face memory performance. Neuroreport, 18, 987-991.

Kosslyn, S. M., Shin, L. M., Thompson, W. L., McNally, R. J., Rauch, S. L., Pitman, R. K., et al. 1996. Neural effects of visualizing and perceiving aversive stimuli: a PET investigation. Neuroreport, 7, 1569-1576.

Kring, A. M., \& Gordon, A. H. 1998. Sex differences in emotion: expression, experience, and physiology. Journal of Personality and Social Psychology, 74, 686-703.

LaBar, K. S., \& Cabeza, R. 2006. Cognitive neuroscience of emotional memory. Nature Reviews Neuroscience, 7, 54-64.

LaBar, K. S., Gatenby, J. C., Gore, J. C., LeDoux, J. E., \& Phelps, E. A. 1998. Human amygdala activation during conditioned fear acquisition and extinction: a mixed-trial fMRI study. Neuron, 20, 937-945.

Lang, P. J., Greenwald, M.K., Bradley, M.M., \& Hamm, A.O. 1993. Looking at pictures: affective, facial, visceral, and behavioral reactions. Psychophysiology, 30, 261-273.

LeDoux, J. 2007. The amygdala. Current Biology, 17, R868-874.

LeDoux, J. E. 2000. Emotion circuits in the brain. Annual Review of Neuroscience, 23, 155-184.

Mackiewicz, K. L., Sarinopoulos, I., Cleven, K. L., \& Nitschke, J. B. 2006. The effect of anticipation and the specificity of sex differences for amygdala and hippocampus function in emotional memory. Proceedings of the National Academy of Sciences of the United States of America, 103, 14200-14205.

Maguire, E. A. 2001. Neuroimaging studies of autobiographical event memory. Philosophical Transactions of the Royal Society B: Biological Sciences, 356, 1441-1451.

Maguire, E. A., \& Frith, C. D. 2003. Lateral asymmetry in the hippocampal response to the remoteness of autobiographical memories. Journal of Neuroscience, 23, 5302-5307.

Mak, A. K., Hu, Z. G., Zhang, J. X., Xiao, Z., \& Lee, T. M. 2009. Sex-related differences in neural activity during emotion regulation. Neuropsychologia, 47, 2900-2908.

Mano, Y., Sugiura, M., Tsukiura, T., Chiao, J. Y., Yomogida, Y., Jeong, H., et al. 2011. The representation of social interaction in episodic memory: a functional MRI study. Neuroimage, 57, 1234-1242.

Maratos, E. J., Dolan, R. J., Morris, J. S., Henson, R. N., \& Rugg, M. D. 2001. Neural activity associated with episodic memory for emotional context. Neuropsychologia, 39, 910-920.

Markowitsch, H. J., \& Staniloiua, A. 2009. Amygdala in action: Relaying biological and social significance to autobiographical memory. Neuropsychologia, 49, 718-733.

Markowitsch, H. J., Thiel, A., Reinkemeier, M., Kessler, J., Koyuncu, A., \& Heiss, W. D. 2000. Right 
amygdalar and temporofrontal activation during autobiographic, but not during fictitious memory retrieval. Behavioural Neurology, 12, 181-190.

Markowitsch, H. J., Vandekerckhove, M. M., Lanfermann, H., \& Russ, M. O. 2003. Engagement of lateral and medial prefrontal areas in the ecphory of sad and happy autobiographical memories. Cortex, 39, 643-665.

Martin, S. J., Grimwood, P. D., \& Morris, R. G. 2000. Synaptic plasticity and memory: an evaluation of the hypothesis. Annual Review of Neuroscience, 23, 649-711.

Mather, M. 2006. Why memories may become more positive as people age. In B. Uttl, N. Ohta \& A. L. Siegenthaler (Eds.), Memory and Emotion: Interdisciplinary Perspectives (pp. 135-159). Blackwell Publishing.

Mather, M. 2007. Emotional arousal and memory binding: An object-based framework. Perspectives on Psychological Science, 2, 33-52.

Mather, M., \& Carstensen, L. L. 2005. Aging and motivated cognition: the positivity effect in attention and memory. Trends in Cognitive Sciences, 9, 496-502.

Mather, M., \& Knight, M. 2005. Goal-directed memory: the role of cognitive control in older adults' emotional memory. Psychology and Aging, 20, 554-570.

Mather, M., \& Nesmith, K. 2008. Arousal-enhanced location memory for pictures. Journal of Memory and Language, 58, 449-464.

Mayberg, H. S. 1997. Limbic-cortical dysregulation: a proposed model of depression. Journal of Neuropsychiatry and Clinical Neurosciences, 9, 471-481.

Mayo, P. R. 1983. Personality traits and the retrieval of positive and negative memories. Personality and Individual Differences, 4, 465-471.

McGaugh, J. L. 2000. Memory - a century of consolidation. Science, 287, 248-251.

McGaugh, J. L. 2004. The amygdala modulates the consolidation of memories of emotionally arousing experiences. Annual Review of Neuroscience, 27, 1-28.

Mickley, K. R., \& Kensinger, E. A. 2008. Emotional valence influences the neural correlates associated with remembering and knowing. Cognitive Affective and Behavioral Neuroscience, 8, 143-152.

Mickley Steinmetz, K. R., Addis, D. R., \& Kensinger, E. A. 2010. The effect of arousal on the emotional memory network depends on valence. Neuroimage, 53, 318-324.

Mickley Steinmetz, K. R., \& Kensinger, E. A. 2009. The effects of valence and arousal on the neural activity leading to subsequent memory. Psychophysiology, 46, 1190-1199.

Morey, R. A., Hariri, A. R., Gold, A. L., Hauser, M. A., Munger, H. J., Dolcos, F., et al. 2011. Serotonin transporter gene polymorphisms and brain function during emotional distraction from cognitive processing in posttraumatic stress disorder. BMC Psychiatry, 11, doi:10.1186/1471-244x-11-76.

Murty, V. P., Ritchey, M., Adcock, R. A., \& LaBar, K. S. 2010. Reprint of: fMRI studies of successful emotional memory encoding: a quantitative meta-analysis. Neuropsychologia, 49, 695-705.

Muscatell, K. A., Addis, D. R., \& Kensinger, E. A. 2010. Self-involvement modulates the effective connectivity of the autobiographical memory network. Social Cognitive and Affective Neuroscience, 5, 68-76.

Nader, K., Schafe, G. E., \& Le Doux, J. E. 2000. Fear memories require protein synthesis in the amygdala for reconsolidation after retrieval. Nature, 406, 722-726.

Northoff, G., Schneider, F., Rotte, M., Matthiae, C., Tempelmann, C., Wiebking, C., et al. 2009. Differential parametric modulation of self-relatedness and emotions in different brain regions. Human Brain Mapping, 30, 369-382.

O'Doherty, J. P. 2004. Reward representations and reward-related learning in the human brain: insights from neuroimaging. Current Opinion in Neurobiology, 14, 769-776.

Ochsner, K. N. 2000. Are affective events richly recollected or simply familiar? The experience and process of recognizing feelings past. Journal of Experimental Psychology: General, 129, 242-261.

Ochsner, K. N., \& Gross, J. J. 2005. The cognitive control of emotion. Trends in Cognitive Sciences, 9, 242249.

Ochsner, K. N., Knierim, K., Ludlow, D., Hanelin, J., Ramachandran, T., \& Mackey, S. 2004. Reflecting upon feelings: An fMRI study of neural systems supporting the attribution of emotion to self and other. Journal of Cognitive Neuroscience, 16, 1748-1772.

Ochsner, K. N., \& Schacter, D. L. 2000. A social cognitive neuroscience approach to emotion and memory. 
In J. C. Borod (Ed.), The Neuropsychology of Emotion (pp. 163-193). New York: Oxford University Press.

Ochsner, K. N., \& Schacter, D. L. 2003. Remembering emotional events: A social cognitive neuroscience approach. In R. J. Davidson, H. Goldsmith \& K. R. Scherer (Eds.), Handbook of the Affective Sciences (pp. 643-660). New York: Oxford University Press.

Oddo, S., Lux, S., Weiss, P. H., Schwab, A., Welzer, H., Markowitsch, H. J., et al. 2010. Specific role of medial prefrontal cortex in retrieving recent autobiographical memories: An fMRI study of young female subjects. Cortex, 46, 29-39.

Owen, A. M., Herrod, N. J., Menon, D. K., Clark, J. C., Downey, S. P., Carpenter, T. A., et al. 1999. Redefining the functional organization of working memory processes within human lateral prefrontal cortex. European Journal of Neuroscience, 11, 567-574.

Paller, K. A., Kutas, M., Shimamura, A. P., \& Squire, L. R. 1987. Brain responses to concrete and abstract words reflect processes that correlate with later performance on a test of stem-completion priming. Electroencephalography and Clinical Neurophysiology. Supplement 40, 360-365.

Paller, K. A., \& Wagner, A. D. 2002. Observing the transformation of experience into memory. Trends in Cognitive Sciences, 6, 93-102.

Petrides, M. 1995. Functional organization of the human frontal cortex for mnemonic processing. Evidence from neuroimaging studies. Annals of the New York Academy of Sciences, 769, 85-96.

Phan, K. L., Taylor, S. F., Welsh, R. C., Ho, S. H., Britton, J. C., \& Liberzon, I. 2004. Neural correlates of individual ratings of emotional salience: a trial-related fMRI study. Neuroimage, 21, 768-780.

Phan, K. L., Wager, T., Taylor, S. F., \& Liberzon, I. 2002. Functional neuroanatomy of emotion: a metaanalysis of emotion activation studies in PET and fMRI. Neuroimage, 16, 331-348.

Phelps, E. A. 2004. Human emotion and memory: interactions of the amygdala and hippocampal complex. Current Opinion in Neurobiology, 14, 198-202.

Phelps, E. A., LaBar, K. S., Anderson, A. K., O’Connor, K. J., Fulbright, R. K., \& Spencer, D. D. 1998. Specifying the contributions of the human amygdala to emotional memory: A case study. Neurocase, 4, 527-540.

Phelps, E. A., \& LeDoux, J. E. 2005. Contributions of the amygdala to emotion processing: from animal models to human behavior. Neuron, 48, 175-187.

Phillips, L. H., MacLean, R. D., \& Allen, R. 2002. Age and the understanding of emotions: neuropsychological and sociocognitive perspectives. Journals of Gerontology Series B: Psychological Sciences and Social Sciences, 57, P526-530.

Piefke, M., Weiss, P. H., Zilles, K., Markowitsch, H. J., \& Fink, G. R. 2003. Differential remoteness and emotional tone modulate the neural correlates of autobiographical memory. Brain, 126, 650-668.

Poldrack, R. A., Wagner, A. D., Prull, M. W., Desmond, J. E., Glover, G. H., \& Gabrieli, J. D. 1999. Functional specialization for semantic and phonological processing in the left inferior prefrontal cortex. Neuroimage, 10, 15-35.

Prince, S. E., Daselaar, S. M., \& Cabeza, R. 2005. Neural correlates of relational memory: successful encoding and retrieval of semantic and perceptual associations. Journal of Neuroscience, 25, 12031210 .

Proverbio, A. M., Adorni, R., Zani, A., \& Trestianu, L. 2008. Sex differences in the brain response to affective scenes with or without humans. Neuropsychologia.

Proverbio, A. M., Zani, A., \& Adorni, R. 2008. Neural markers of a greater female responsiveness to social stimuli. BMC Neuroscience, 9, 56.

Quirarte, G. L., Roozendaal, B., \& McGaugh, J. L. 1997. Glucocorticoid enhancement of memory storage involves noradrenergic activation in the basolateral amygdala. Proceedings of the National Academy of Sciences of the United States of America, 94, 14048-14053.

Richardson, M. P., Strange, B. A., \& Dolan, R. J. 2004. Encoding of emotional memories depends on amygdala and hippocampus and their interactions. Nature Neuroscience, 7, 278-285.

Ritchey, M., Dolcos, F., \& Cabeza, R. 2008. Role of Amygdala Connectivity in the Persistence of Emotional Memories Over Time: An Event-Related fMRI Investigation. Cerebral Cortex, 18, 2494-2504.

Ritchey, M., Labar, K. S., \& Cabeza, R. 2011. Level of Processing Modulates the Neural Correlates of Emotional Memory Formation. Journal of Cognitive Neuroscience, 23, 757-771.

Rolls, E. T. 2004. The functions of the orbitofrontal cortex. Brain and Cognition, 55, 11-29. 
Roozendaal, B., \& McGaugh, J. L. 1997. Glucocorticoid receptor agonist and antagonist administration into the basolateral but not central amygdala modulates memory storage. Neurobiology of Learning and Memory, 67, 176-179.

Rosen, B. R., Buckner, R. L., \& Dale, A. M. 1998. Event-related functional MRI: past, present, and future. Proceedings of the National Academy of Sciences of the United States of America, 95, 773-780.

Rubin, D. C., Berntsen, D., \& Bohni, M. K. 2008. A memory-based model of posttraumatic stress disorder: evaluating basic assumptions underlying the PTSD diagnosis. Psychological Review, 115, 985-1011.

Ruiz-Caballero, J. A., \& Bermudez, J. 1995. Neuroticism, mood, and retrieval of negative personal memories. Journal of General Psychology, 122, 29-35.

Russell, J. 1980. A circumplex model of affect. Journal of Personality and Social Psychology, 39, 11611178.

Rusting, C. L. 1999. Interactive effects of personality and mood on emotion-congruent memory and judgment. Journal of Personality and Social Psychology, 77, 1073-1086.

Sakaki, M., Niki, K., \& Mather, M. 2012. Beyond arousal and valence: The importance of the biological versus social relevance of emotional stimuli. Cognitive Affective and Behavioral Neuroscience, 12, 115-139.

Schlagman, S., Schulz, J., \& Kvavilashvili, L. 2006. A content analysis of involuntary autobiographical memories: examining the positivity effect in old age. Memory, 14, 161-175.

Seidlitz, L., \& Diener, E. 1998. Sex differences in the recall of affective experiences. Journal of Personality and Social Psychology, 74, 262-271.

Sergerie, K., Lepage, M., \& Armony, J. L. 2005. A face to remember: emotional expression modulates prefrontal activity during memory formation. Neuroimage, 24, 580-585.

Sergerie, K., Lepage, M., \& Armony, J. L. 2006. A process-specific functional dissociation of the amygdala in emotional memory. Journal of Cognitive Neuroscience, 18, 1359-1367.

Shafer, A., Iordan, A., Cabeza, R., \& Dolcos, F. 2011. Brain imaging investigation of the memory-enhancing effect of emotion. Journal of Visualized Experiments, 51, doi:10.3791/2433.

Shallice, T., Fletcher, P., Frith, C. D., Grasby, P., Frackowiak, R. S., \& Dolan, R. J. 1994. Brain regions associated with acquisition and retrieval of verbal episodic memory. Nature, 368, 633-635.

Sharot, T. 2011. The optimism bias. Current Biology, 21, R941-945.

Sharot, T., Delgado, M. R., \& Phelps, E. A. 2004. How emotion enhances the feeling of remembering. Nature Neuroscience, 7, 1376-1380.

Sharot, T., Martorella, E. A., Delgado, M. R., \& Phelps, E. A. 2007. How personal experience modulates the neural circuitry of memories of September 11. Proceedings of the National Academy of Sciences of the United States of America, 104, 389-394.

Sharot, T., Riccardi, A. M., Raio, C. M., \& Phelps, E. A. 2007. Neural mechanisms mediating optimism bias. Nature, 450, 102-105.

Smith, A. P., Henson, R. N., Dolan, R. J., \& Rugg, M. D. 2004. fMRI correlates of the episodic retrieval of emotional contexts. Neuroimage, 22, 868-878.

Smith, A. P., Stephan, K. E., Rugg, M. D., \& Dolan, R. J. 2006. Task and content modulate amygdalahippocampal connectivity in emotional retrieval. Neuron, 49, 631-638.

Somerville, L. H., Wig, G. S., Whalen, P. J., \& Kelley, W. M. 2006. Dissociable medial temporal lobe contributions to social memory. Journal of Cognitive Neuroscience, 18, 1253-1265.

St. Jacques, P.L., Dolcos, F., \& Cabeza, R. 2009. Effects of aging on functional connectivity of the amgydala during subsequent memory for negative pictures: A network analysis of fMRI data. Psychological Science, 20, 74-84.

Strange, B. A., \& Dolan, R. J. 2004. Beta-adrenergic modulation of emotional memory-evoked human amygdala and hippocampal responses. Proceedings of the National Academy of Sciences of the United States of America, 101, 11454-11458.

Strange, B. A., Hurlemann, R., \& Dolan, R. J. 2003. An emotion-induced retrograde amnesia in humans is amygdala- and beta-adrenergic-dependent. Proceedings of the National Academy of Sciences of the United States of America, 100, 13626-13631.

Talarico, J. M., LaBar, K. S., \& Rubin, D. C. 2004. Emotional intensity predicts autobiographical memory experience. Memory and Cognition, 32, 1118-1132.

Talmi, D., Anderson, A. K., Riggs, L., Caplan, J. B., \& Moscovitch, M. 2008. Immediate memory 
consequences of the effect of emotion on attention to pictures. Learning and Memory, 15, 172-182.

Taylor, S. F., Liberzon, I., Fig, L. M., Decker, L. R., Minoshima, S., \& Koeppe, R. A. 1998. The effect of emotional content on visual recognition memory: a PET activation study. Neuroimage, 8, 188-197.

Thoresen, C., Jensen, J., Sigvartsen, N. P., Bolstad, I., Server, A., Nakstad, P. H., et al. 2011. Arousal Modulates Activity in the Medial Temporal Lobe during a Short-Term Relational Memory Task. Frontiers in Human Neuroscience, 5, 177.

Touryan, S. R., Johnson, M. K., Mitchell, K. J., Farb, N., Cunningham, W. A., \& Raye, C. L. 2007. The influence of self-regulatory focus on encoding of, and memory for, emotional words. Social Neuroscience, 2, 14-27.

Tsukiura, T., \& Cabeza, R. 2008. Orbitofrontal and hippocampal contributions to memory for face-name associations: The rewarding power of a smile. Neuropsychologia, 46, 2310-2319.

Tsukiura, T., \& Cabeza, R. 2011a. Remembering beauty: roles of orbitofrontal and hippocampal regions in successful memory encoding of attractive faces. Neuroimage, 54, 653-660.

Tsukiura, T., \& Cabeza, R. 2011b. Shared brain activity for aesthetic and moral judgments: implications for the Beauty-is-Good stereotype. Social Cognitive and Affective Neuroscience, 6, 138-148.

Tsukiura, T., Shigemune, Y., Nouchi, R., Kambara, T., \& Kawashima, R. 2012, in press. Insular and hippocampal contributions to remembering people with an impression of bad personality. Social Cognitive and Affective Neuroscience, http://www.ncbi.gov/pubmed/22349799.

Tulving, E. 1985. Memory and consciousness. Canadian Psychology, 26, 1-12.

Vandekerckhove, M. M., Markowitsch, H. J., Mertens, M., \& Woermann, F. G. 2005. Bi-hemispheric engagement in the retrieval of autobiographical episodes. Behavioural Neurology, 16, 203-210.

Vazdarjanova, A., \& McGaugh, J. L. 1998. Basolateral amygdala is not critical for cognitive memory of contextual fear conditioning. Proceedings of the National Academy of Sciences of the United States of America, 95, 15003-15007.

Vuilleumier, P., Richardson, M. P., Armony, J. L., Driver, J., \& Dolan, R. J. 2004. Distant influences of amygdala lesion on visual cortical activation during emotional face processing. Nature Neuroscience, 7, 1271-1278.

Weis, S., Klaver, P., Reul, J., Elger, C. E., \& Fernandez, G. 2004. Temporal and cerebellar brain regions that support both declarative memory formation and retrieval. Cerebral Cortex, 14, 256-267.

Young, G. C., \& Martin, M. 1981. Processing of information about self by neurotics. British Journal of Clinical Psychology, 20, 205-212.

(Manuscript received March 11, 2012; Revision accepted March 12, 2012) 